\title{
Disclosing Water-Energy-Economics Nexus in Shale Gas Development
}

\author{
Andrés J. Calderón ${ }^{\mathrm{a}, \dagger}$, Omar J. Guerrab ${ }^{\mathrm{b}} \uparrow, \S$, Lazaros G. Papageorgiou ${ }^{\mathrm{a}}$, \\ Gintaras V. Reklaitisb,ł \\ a Department of Chemical Engineering, University College London, London WC1E 7JE, UK \\ bSchool of Chemical Engineering, Purdue University, West Lafayette IN 47907 USA. \\ ‡Corresponding author. E-mail address: reklaiti@purdue.edu (G.V. Reklaitis).
}

${ }^{\dagger}$ These authors contributed equally to this work

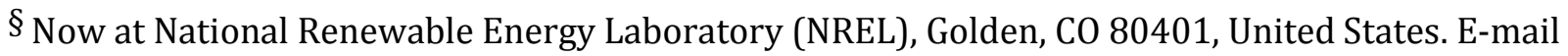
address: OmarJose.GuerraFernandez@nrel.gov

\begin{abstract}
Shale gas has gained importance in the energy landscape in recent decades. However, its development has raised environmental concerns, especially, those associated with water management. Thus, the assessment of water management aspects which inevitably impact the economic aspects, is crucial in evaluating the merits of any project exploiting this energy source. This paper provides a review of the economic and environmental implications of shale gas development around the world. Furthermore, to demonstrate the interplay between the various technical, environmental and economic factors in concrete terms, we report on a specific set of case studies conducted using an integrated decisionsupport tool that has been implemented to model and optimize shale gas development projects. The case study results confirm that the gas breakeven price decreases with expansion in scale of the shale gas development, i.e. increasing the number of well-pads in the system. However, scale also increases the options for water re-use and recycle in drilling and fracturing operations, which can result in lower freshwater withdrawal intensity. Moreover, under water scarcity scenarios, the choice of well-pad designs that are
\end{abstract}


inherently less water intensive was found to be more cost-effective than water re-use or/and recycle strategies at reducing net freshwater demand. Similar trends were observed when the impact of wastewater quality, i.e. total dissolved solids concentration, on the optimal development strategy of shale gas plays was investigated. The results of these case studies reveal that greater efforts are needed at characterizing freshwater availability and wastewater quality for the evaluation of both the economic and environmental aspects of shale gas development.

\section{Introduction}

The depletion of conventional fossil fuel reserves together with the growing demand for primary energy have spurred the development of new energy sources, with shale gas and shale oil among the unconventional fuels receiving most attention. Even though the development of these unconventional fossil fuels has brought new business opportunities to the energy sector, their exploitation relies on the implementation of more sophisticated and costly production techniques, specifically, horizontal drilling and hydraulic fracturing, which make their economics especially susceptible to volatile prices in the spot market. Additionally, the implementation of artificial stimulation techniques, used in hydraulic fracturing operations, has raised concerns regarding potential negative environmental impacts, especially the depletion and possible degradation of fresh water resources. Thus, a rigorous quantification of the trade-offs associated with the development of shale gas plays is essential for evaluating the economics of these unconventional fossil fuel projects as well as for formulating policies and regulations for their adequate exploitation and development [1].

In particular, shale gas development has drawn the attention of countries around the world, stimulated by its observed impacts in the United States not only on the economy but also on the increasing burden on water resources required for fracturing operations $[2,3]$. Accordingly, this increasing interest has resulted in numerous research studies addressing different aspects regarding the exploitation of shale gas resources. Some researchers have focused on the geological characterization, including prospectivity assessment [4-6] and productivity evaluation based on the identification of the naturally-fracture networks [7]. 
Reservoir modeling and simulation techniques have been implemented to investigate the productivity of shale gas plays by integrating petrophysical and geomechanical characterization along with different artificial stimulation strategies [8,9]. Moreover, the economic assessment of shale gas plays has also drawn the attention of the research community. Simulation-based and data driven tools have been reported for the preliminary evaluation of shale gas development $[10,11]$. Furthermore, given the complexity of the decision-making problem, optimization models have been developed and implemented for the tactical and strategic planning of shale gas fields and supply chains [12-17]. In addition to modeling, simulation, and economic evaluation of shale gas resources, the assessment of environmental impacts, in terms of $\mathrm{CO}_{2}$ emissions, associated with the development of shale gas resources, has also been subject of extensive research [18-20]. Wastewater management is another crucial aspect, which is being considered in the development of shale gas plays. However, despite the extensive studies reported to date on shale gas issues, the integration of water management within the design and planning of shale gas supply chains remains one of the key areas where additional research efforts are needed. In particular, the interaction between the well-pad configuration and water management strategies could reveal synergies that can be exploited in the planning of the shale gas supply chain. To address this gap, a comprehensive optimization framework, presented in ref. [13], has been developed in order to integrate the decisions relevant to shale gas production, transportation and processing together with the decisions associated with water management, including wastewater quality issues. This article aims to: 1) provide a comprehensive review of the challenges and implications regarding sustainability and economic aspects associated with the development of shale gas as an energy resource at the global, regional, and local scales, and 2) develop and implement a quantitative modelbased system analysis for elucidating regional, and local aspects by investigating the nexus of water-energy-economy of scale. The results reveal synergies between the scale of the shale gas development, the design of well-pads and the impact of water management on the economic performance of shale gas operations. 


\section{Challenges and implications in shale gas developments}

\subsection{Global context}

\subsubsection{Shale gas resources, gas market, and water stress}

Natural gas, including unconventional gas, is a key energy source, supplying about $21.4 \%(\sim 3,507$ billion cubic meters $(\mathrm{bcm}))$ of world primary energy demand in 2013 [21]. The United States was the largest natural gas consumer accounting for roughly $27.1 \%$ of the global demand, followed by Russia, Europe, Middle East, and China with shares of $17.5 \%, 17.2 \%, 15.3 \%$, and 6.3\%, respectively (see Figure 1). Moreover, natural gas is the fastest growing fossil fuel and is expected to represent roughly $23.6 \%$ of the global primary energy demand by 2040 [21], giving natural gas an even more prominent role in the global energy mix. By way of comparison, oil and coal will represent about $26.4 \%$ and $24.6 \%$ of the world primary energy demand by 2040. Despite China's low gas consumption in 2013 by comparison to the global gas demand, China and the Middle East are expected to be the dominant areas of gas demand growth, together accounting for $\sim 44.6 \%$ of total gas demand increase by 2040 . Specifically, by 2040 China's gas consumption will increase by more than three-fold with respect to the 2013 level, reaching $15.0 \%$ of the global gas demand. This increase, in combination with a reduction in gas demand in Russia and Europe, will position China as the third largest gas consumer, behind only the United States and the Middle East, which are expected to account for about $21.5 \%$ and $18.7 \%$ of the global gas demand by 2040, respectively [21]. Consequently, the global gas market is expected to expand. This expansion will be mostly driven by Liquified Natural Gas (LNG) trade, which is increasing faster than delivery of gas via pipelines. The main reason is that LNG enables a worldwide distribution of natural gas, adding flexibility to the gas market by allowing trading of the commodity without requiring fixed distribution infrastructure with long-term agreements between suppliers and consumers. However, shale gas could be produced at advantageous domestic prices in comparison to importing gas as LNG (between 2010 and 2014 the prices for shale gas varied from 2 \$/MBtu to 6 \$/MBtu, whereas for LNG prices ranged from 10 \$MBtu to 18 \$/MBtu). Moreover, the merit of developing these energy sources can be addressed through metrics such as the energy penalty. For instance, the efficiency for delivering natural gas via LNG is $\sim 75 \%$ (energy 
penalty of about 25\%), while for gas pipeline it ranges from $85 \%$ to $90 \%$ (energy penalty ranging from $10 \%$ to $15 \%$ ] [22]. In addition, the energy return on investment (EROI) also provides valuable information regarding primary energy sources [23-25]. The EROI is estimated as the ratio energy outputs/energy inputs associated with the production of a given energy source and is intended to measure its quality [24-26]. As a reference, the EROI for shale gas production at the Marcellus shale gas play in the United States is estimated to be $\sim 85: 1$ [27], whereas the EROI for oil and natural gas extraction in China is estimated to be $\sim 10: 1$ [24]. Moreover, the EROI for coal production is China is $\sim 27: 1$, which is considerable higher than that of oil and natural gas extraction [24]. Note that there is a lack of research regarding the EROI of LNG, which is case specific.

Regarding the current global gas market, in 2013, the world's total gas imports was $1044.1 \mathrm{bcm}$, of which $30.7 \%$ was imported as LNG and 69.3\% through pipelines [28]. Currently, Qatar is by far the largest LNG exporter accounting for $31.9 \%$ of the total export in 2013, while Malaysia and Australia supplied 10.5\% and 9.8\%, respectively. New projects are being commissioned in countries such as Australia, Canada, and United States and therefore a higher share of LNG in the world's gas export is expected in the next few years [29]. Among the major importers, Asia Pacific (including Japan, South Korea, and Taiwan) dominates the LNG imports accounting for $63.7 \%$ of the total LNG imports in 2013. In the same year, Asia (including China and India) had a similar LNG market share as Europe of $13.9 \%$ and $13.5 \%$, respectively. As far as gas imports through pipelines, Europe continues to be the major importer with a share of $51.2 \%$ of gas delivered via pipelines.

In 2013, the net import of gas in the United States was only $4.3 \%$ of the gas consumption; a figure that has been steadily decreasing since the production of shale gas kicked off in 2007. The production of shale gas has brought about important changes in the role of the United States in the global energy market, therefore one would expect that the government would continue to support the development of these resources. In South America, the net import of gas to Argentina constituted $19.9 \%$ of the total gas consumption in that country in 2013 . Around $45.5 \%$ of the gas was imported through pipelines, while $54.5 \%$ was imported as LNG. Since it has the world's second largest shale gas resources, one would expect that Argentina would soon be exploiting its vast resources at commercial 
scale, not only to supply the local demand but also to enter the growing LNG market. Australia, which is already the third largest exporter of LNG, is seventh in terms of shale resources. Therefore, the development of shale gas in that country offers a great opportunity to expand its market share through further growth in LNG export.

In 2013, 15 countries of the European Union, EU-28, imported at least $80 \%$ of their corresponding gas consumption, making them highly dependent on gas imports. The major suppliers are Russia, Norway and Algeria, who are providing 39.0\%, 29.5\% and 12.8\% of the total Europe's gas imports. Europe has 13,327 bcm of shale gas reserves, which are enough to supply the 2040 Europe's gas demand for about $\sim 28$ years. Although shale gas presents an excellent alternative to alleviate European energy dependency, the development of these resources is facing strong public opposition and its exploitation has been banned in some countries, i.e. Bulgaria, Germany and France [30]. In the case of Russia, despite having significant shale gas reserves, Russia holds the largest reserves of conventional gas, enough to cover in 2013 the local demand and supply about 18\% of the international gas trade. Therefore, the exploitation of shale gas in Russia seems unlikely in the foreseeable future. In Africa, South Africa imported 61.3\% of its gas demand mainly from Mozambique. This country is seeking to develop its natural gas supply chain and for that reason the government is considering projects for regasification plants for importing LNG. Since South Africa is in the top ten of countries with the largest shale gas reserves, the exploration of shale gas could be a strong alternative for supplying its gas demand. China is an important player in the global gas market. In 2013, 23.5\% of its gas demand was supplied by imports mainly from Turkmenistan, Qatar, and Australia. Its growing economy has been driving up primary energy consumption, which has been supplied via an increase in gas imports. In an attempt to restrain the increasing imports, the government is actively supporting the exploitation of shale gas. As a result, in 2015, China produced $4.5 \mathrm{bcm}$ of shale gas, three times more than in 2014 [31]. Furthermore, an initial target for producing $60 \mathrm{bcm}$ was set for 2020 [32], however, companies involved in the exploration of shale gas in China have reported technical difficulties due to the complex geology of the prospective areas and limited infrastructure. Therefore, this ambitious target was re-evaluated by the Chinese government and reduced to $30 \mathrm{bcm}$ [33]. 


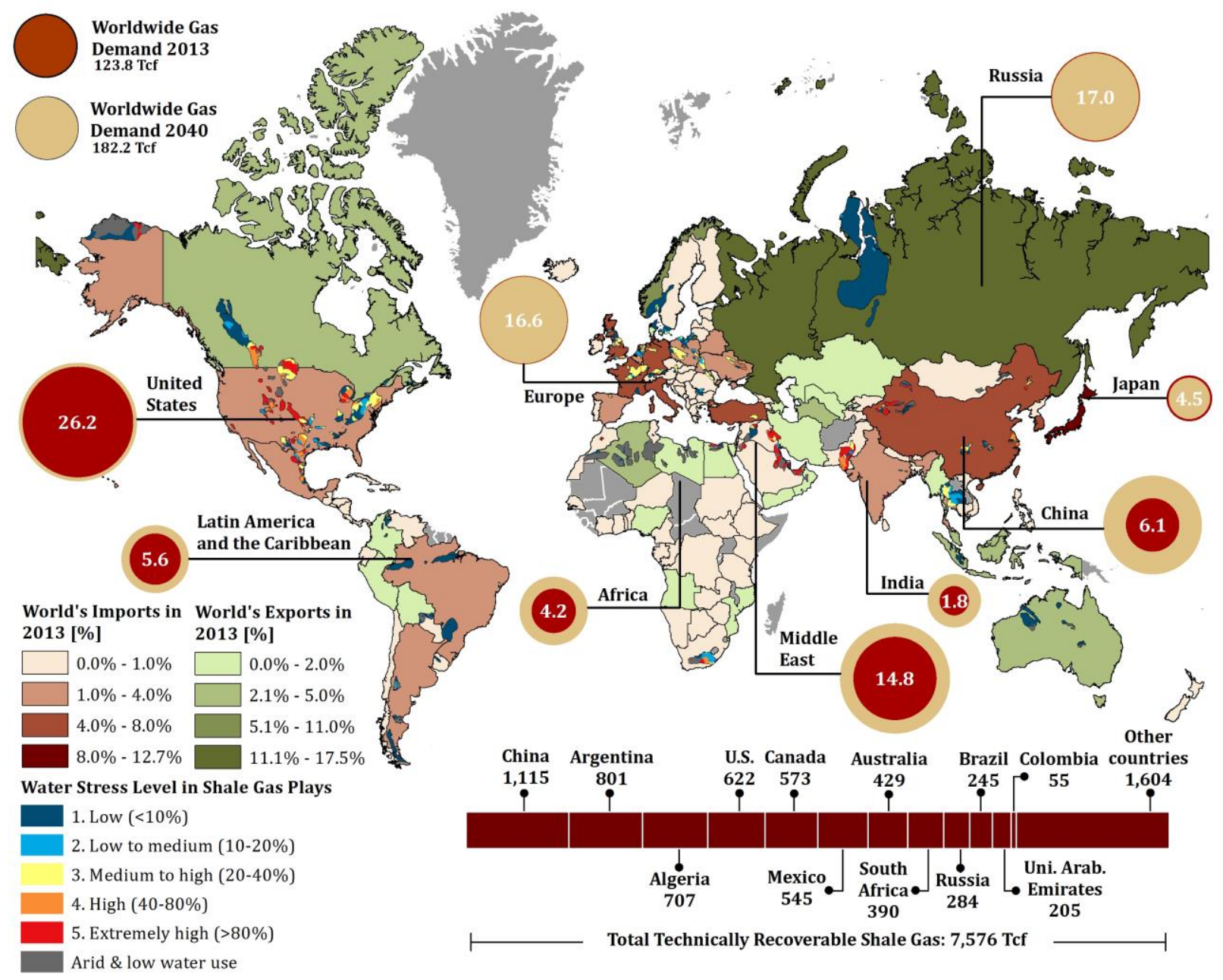

Figure 1. Global gas demand and supply [21,28], shale gas reserves [34], and water stress $[35,36]$. Numbers inside the bubbles indicate the natural gas demand in 2013.

The growing demand for natural gas together with the depletion of conventional gas reserves has spurred the development of unconventional gas, in particular, shale gas. Unconventional gas, mostly shale gas, is expected to represent $\sim 60 \%$ of the total growth in gas supply from 2013 to 2040 [21]. The distribution of prospective and developed shale gas plays around the world is shown in Figure 1. In 2014, the International Energy Agency (IEA) estimated the total technically recoverable shale gas to be 7,576 trillion cubic feet (Tcf) (227.3 tcm), which would be enough to supply the world's 2040 gas demand for $\sim 40$ years. China holds the largest shale gas reserves, comprising around $14.7 \%$ of the total availability, followed by Argentina, Algeria, and United States. with 10.6\%, 9.3\%, and 8.2\% of the world's shale gas reserves, respectively. Currently, the majority of plays in 
commercial shale gas operation are located in the United States, and only a minor fraction is located in Canada and China.

The development of shale gas has had remarkable repercussions on the U.S. economy and this has caught the attention of governments around the world, who now are seeking to replicate the precedent set by the United States in their economies. Nonetheless, the opportunities and urgency for developing shale gas resources are specific for every country. Gas imports and future gas demand can provide some hints of the relative importance for a country to develop its shale gas resources.

It appears that shale gas holds the key for nations with shale resources to secure a short-term energy supply. However, the development of shale gas does come at potential cost in terms of its environmental impact. The exploitation of these resources could increase the stress on local fresh water sources; a crucial challenge that must be systematically addressed [37]. It has been reported that $38 \%$ of the global shale gas resources are affected by limited fresh water access which can curb the successful development of these resources [35]. From the list of countries with the largest shale gas reserves shown in Figure 1, China, Mexico and South Africa, are, on average, under high water stress levels, and Algeria and Saudi Arabia are classified to be in the arid category. In China, $60 \%$ of the shale resources are located in areas with high or extremely high water stress. In the case of Mexico and South Africa these figures are 61\% and 75\%, respectively. In Algeria more than $90 \%$ of the prospective areas are located in the Sahara desert, while in Saudi Arabia $100 \%$ of the shale plays are placed in arid areas. Europe has a comparative advantage in this respect, since most of the prospective areas for shale gas production are classified in the first three categories of water stress: low, low to medium, and medium to high. This resource quandary presents significant challenges not only in terms of environmental aspects, but also in social and economic elements, which require that governments and decision makers join in efforts to establish regulatory frameworks that allow the sustainable development of shale gas while also securing the water supply necessary for agriculture, industry and domestic consumption. 


\subsubsection{Decoupling of fuel prices}

Exploitation of shale gas resources dates back to 1800's when several wells were drilled in shallow shale formations in the Appalachian and Michigan basins in the United States [38]. However, their further development was overshadowed by the production of conventional fossil fuels. During the 1970's alternative hydraulic fracturing techniques were tested in the Barnett Shale Play, Texas and by 2000 about 726 vertical wells had been drilled. Horizontal drilling techniques, previously developed for conventional reservoirs, were implemented along with multistage fracturing techniques. The first shale gas wells featuring this design appeared in 2003 in the Barnett Shale basin. The combination of these techniques has been an extraordinary innovation that allowed the development of new reserves thought previously to be either impossible or non-profitable for exploitation. The commercial success in the Barnett Shale Play together with high crude oil and natural gas prices, encouraged oil and gas companies to explore and develop other shale basins such as the Hayneville, Fayetteville, Woodford, Marcellus, among others. Drilling and fracturing techniques have been in continuing development with multilateral wells one of the latest advances. Certainly, during the last decade the production of shale gas has progressively altered the energy mix in the United States. In 2007, 7.67\% of the total gross gas withdrawals occurred from shale gas wells. In the following three years, the share of shale gas increased substantially to $20.4 \%$ and by 2015 it reached $46.3 \%$. This has influenced significantly the economy and energy security of the United States $[39,40]$. For instance, gas imports have experienced a drop of $41.0 \%$ by 2015 after reaching a peak of $4.61 \mathrm{Tcf}$ in 2007 [41]. Moreover, since 2000, natural gas exports have been steadily increasing registering an increase of almost 7-fold by 2015 [42]. Regarding energy security, shale gas development could enhance natural gas security in Europe [43,44], whereas the exploitation of domestic shale gas resources is likely to have a minor effect on China's natural gas security [25].

As in any commodity market, the increase in supply usually is reflected in lower prices, as can be seen when the production of shale gas in the United States is compared with the price of Henry Hub natural gas (see Figure 2a). The availability of cheaper natural gas is also transforming the U.S. power sector. For instance, the net electricity generation from 
natural gas plants has increased from 567.3 TWh in 2003 to 1,240.9 TWh in 2015 (an increase of more than two-fold or 673.6 TWh). By contrast, net electricity generation from coal power plants has decreased from 1,952.7 TWh to 1,343.9 TWh (a drop of about 31.2\% or 608.8 TWh) in the same time period [45]. The U.S. shale gas revolution has also influenced the global chemical industry. For instance, in 2013 a total investment of $\$ 71.7$ billion in 97 projects related to the petrochemical sector was announced spanning the period 2010-2020, with roughly half of the investments coming from foreign companies [46]. In 2015, the total number of projects increased to 226 with a corresponding investment of $\$ 138$ billion of which $61 \%$ is coming from companies based outside the U.S [47].
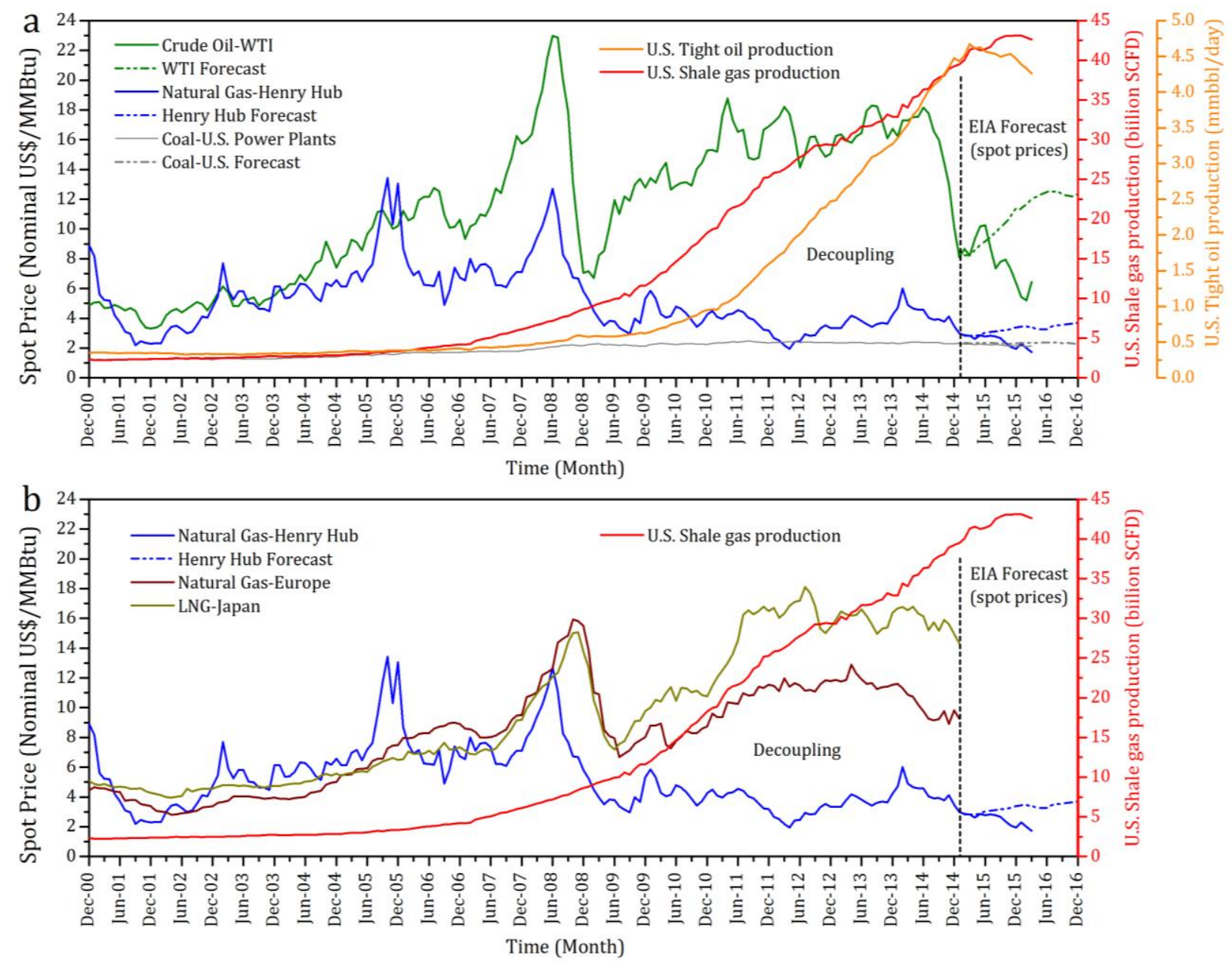

Figure 2. Effects of shale gas and oil production in global fossil fuel market: (a) U.S. unconventional fossil fuel production [48], prices forecast [49], and spot prices for coal [49], oil [50], and gas [51]. (b) U.S. shale gas production [48], prices forecast [49], and spot 
prices of natural gas in different markets [51,52]. Data is provided as supporting information.

Shale gas is not the only unconventional energy source that has caught the attention of oil and gas companies. Tight oil reserves are being developed in parallel with shale gas and these developments are displaying similar trends in the last decade. For example, in 2007, $8.4 \%$ of the total crude oil production in United States was associated with tight oil. Since then, the share of tight oil has increased, reaching $48.2 \%$ in 2015.

The exploitation of unconventional resources (shale gas and tight oil) in the United States, has brought about economic consequences not only at the national level but also at the global scale. For example, tight oil has played a major role in almost doubling the total crude oil production in the United States from 2007 to 2015 [53]. This scenario in combination with other factors such as aggressive policies of major oil producers for securing their global market share, resulted in a surplus of oil production [49] that caused the abrupt reduction of $60.7 \%$ in the oil price over a time period of just two years (2014 and 2015). As a consequence, the production of tight oil, which in general entails higher production costs by comparison to conventional oil, was affected by the low prices causing a shift in the production rate since 2015 (see Figure 2a). Regarding the gas market, an interesting phenomenon has been occurring since 2008, in which the price of gas in the United States (tracked by the Henry Hub index), that historically has mirrored the behavior of the oil price, has decoupled and it is no longer affected by the variability in the oil price. Moreover, the gas price variability is comparatively lower than in previous years. It is reasonable to point to the increasing production of shale gas during the last decade as the main cause of this situation. As a consequence, the production of shale gas has not been noticeably affected by low oil prices in the last years. Coal, an important traditional source of primary energy, has shown a stable behavior along the last 15 years, and its price remains unaffected by the oil and gas market. In addition, a similar pattern can be noticed when the Henry Hub index is compared to the spot market price in Europe and the LNG price in Japan (see Figure 2b). These three markets have shown a strong historical correlation in terms of prices; nonetheless, since 2008 this correlation is no longer valid resulting in gas prices in the United States considerably lower than in Europe or Japan. 
Moreover, it is evident from Figure 2 that the oil and gas market is highly dynamic, which makes price forecasts highly uncertain. Certainly, the United States provides an example of the potential of unconventional resources for impacting the energy mix of a country, especially for countries with abundant shale gas and shale oil reserves, such as China.

\subsubsection{Greenhouse gas emissions: A shift from coal to gas}

Besides the repercussions on commodity prices, energy security, and local and global economy, the development of shale gas resources entails potential environmental impacts that can constitute barriers for the global exploitation of this energy source. For instance, the quantification of greenhouse gas (GHG) emissions and carbon footprint of shale gas as a potential substitute of coal in electricity generation is subject of intense debate [18$20,54,55]$. Indeed, there is not a consensus in the research community regarding the life cycle GHG emissions of shale gas. For instance, findings by Jiang et al. [54] suggested that shale gas use in electricity generation leads to higher GHG emissions than use of conventional gas, although by contrast, Burnham et. al [18] concluded the opposite. While these authors agreed on the potential emission reduction benefits of shale gas in the power sector by comparison to the use of coal, another study reports that the GHG emissions of shale gas surpasses the coal carbon footprint [19]. However, using a meta-analytical approach, a recent study suggested that emissions from electricity generation using shale gas are comparable to that from the use of natural gas, with both having considerably less emissions than those resulting from the use coal [56]. Another source of uncertainty in the analysis of the life cycle GHG emissions of shale gas is the quantification of fugitive methane emissions. If such emissions are proved to be an important fraction of the daily production of a gas field, they can severely affect the environmental benefits of gas over coal [57]. Accordingly, a number of methodologies have been proposed to shed light on this issue $[58,59]$. As a reference, the GHG emissions from electricity generation using shale gas, conventional natural gas, and coal are estimated be $465 \mathrm{~g} \mathrm{CO}_{2} \mathrm{e} / \mathrm{kWh}, 461 \mathrm{~g} \mathrm{CO}_{2} \mathrm{e} / \mathrm{kWh}$, and $980 \mathrm{~g} \mathrm{CO}_{2} \mathrm{e} / \mathrm{kWh}$, respectively [56].

Despite the lack of consensus on these environmental issues, the shift from coal to gas is proceeding in the United States' power sector. Partially as a result of this fuel switch, reported $\mathrm{CO}_{2}$ emissions associated with electricity generation in the United States have 
been decreasing in recent years. For example, $\mathrm{CO}_{2}$ emissions underwent a $16 \%$ drop from 2005 to 2012 in the United States' power sector [60]. However, abundant low cost shale gas could decrease electricity generation from both coal and renewable energies in the power sector [61]. Therefore, the environmental benefits and impacts on climate change of abundant natural gas and the shift from coal to natural gas in the power sector are not clear yet [60-64]. It is noteworthy that even though energy transitions, e.g., from coal to gas, could occur rapidly (in a few years or a decade) at a regional or national scale [65], global energy transitions take many decades to materialize, i.e., from 50 to 60 years $[66,67]$.

\subsection{Regional and Local context}

\subsubsection{Regional water-energy nexus}

The exploitation of shale gas imposes water resource risks, including the depletion, degradation, and contamination, of both underground and surface water sources (See Figure 3). 


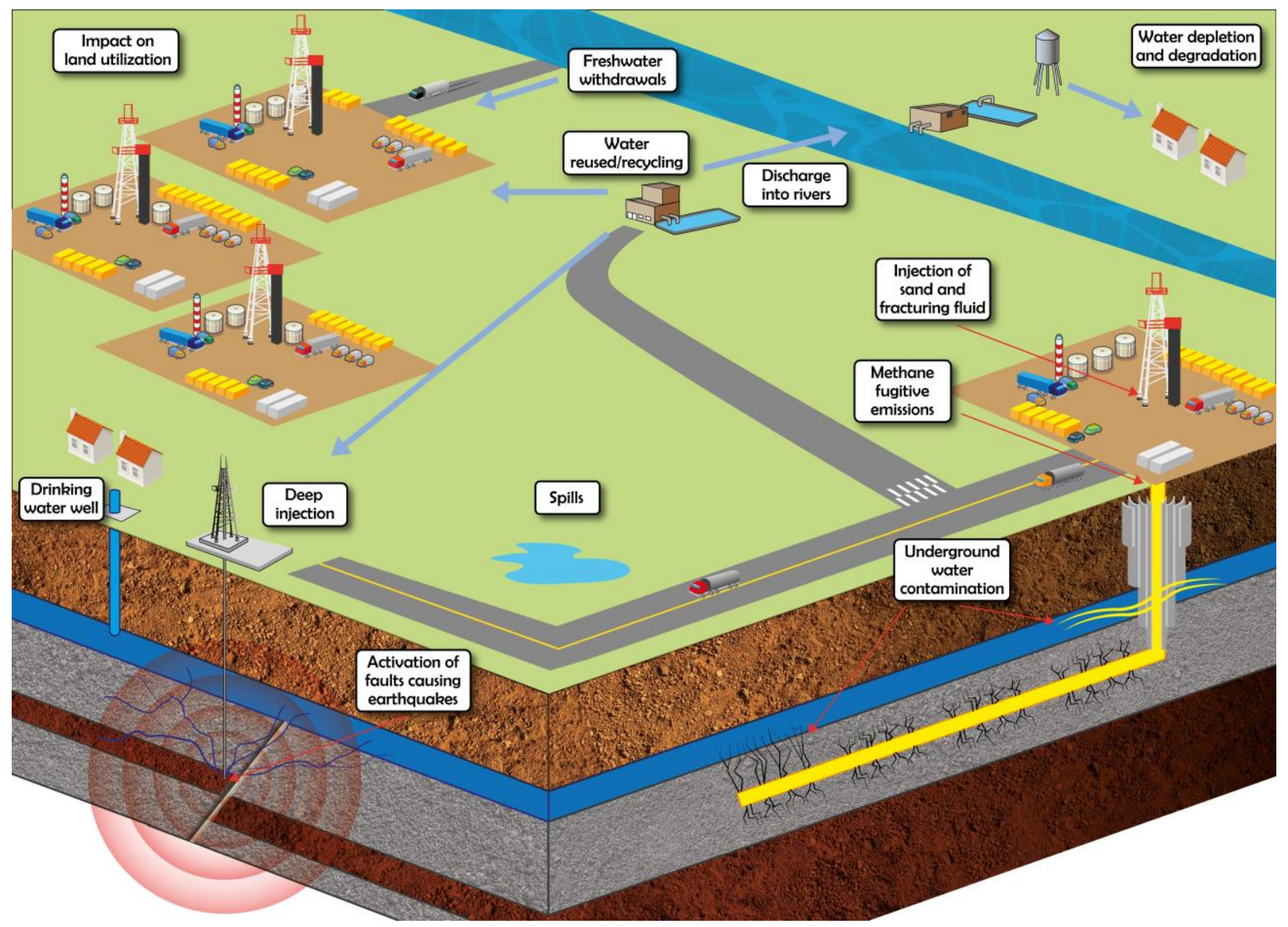

Figure 3. Risks associated with Shale gas developments. Blue arrows represent water flows.

First, fracking operations require large amount of water and consequently water intensity for shale gas development is higher than that of conventional natural gas [68], e.g. water consumption for shale gas in U.S. plays ranges from 13-37 L/GJ (3.63-10.32 gallon/ million Btu) whereas for natural gas it varies from 9.3-9.6 L/GJ (2.59-2.68 gallon/ million Btu) [69]. However, the water intensity of shale gas is on the same order as other fossil energy sources, e.g. 8.3-27.0 L/GJ for coal [70,71]. Moreover, other issues have also been identified [72-75]. For instance, shallow aquifers and groundwater resources can be contaminated with fugitive hydrocarbons. Indeed, studies have associated high hydrocarbon concentrations in drinking water with shale gas production in U.S. plays $[76,77]$. Additionally, inadequate management of wastewater can lead to the contamination of surface water as well as shallow groundwater sources. Also, the accumulation of radioactive and toxic materials in hydraulic fracturing fluid spills or wastewater disposal sites could lead to the degradation of water sources. Furthermore, some studies have 
reported induced seismicity from hydraulic fracturing activities and injection of wastewater from shale gas operations into depleted formations. The latter represents a major risk since it could activate faults that can induce seismic events of considerable magnitude [78,79]. Consequently, water management has been recognized as one of the most important issues associated with the development of shale gas plays [80-82]. Comprehensive reviews of shale gas development risks and environmental impacts, including community impacts and water related issues, are provided in the literature [8388].

Water management encompasses fresh water procurement as well as flowback and produced water (wastewater) disposal or treatment for re-use, recycle, or discharge $[68,89]$. Re-use generally involves treatment of the waste water to remove total suspended solids (TSS) and, if necessary, to reduce total dissolved solids (TDS) concentration. The process is usually implemented on site and the treated water can be blended with freshwater for fracturing of new wells. Depending on the quality of water required for fracturing, the technologies for re-use include basic TSS removal, media filtration, membrane filtration, and ion exchange or nanofiltration to reduce TDS [90]. Recycle of water occurs when the TDS concentration of wastewater is high and therefore it requires implementation of specialized technologies such as distillation and crystallization in order to produce water within the technical specifications required for fracturing operations. Disposal of wastewater through injection in depleted wells is often preferred over recycle because of the low associated costs. However, due to increasingly strict regulations, the injection into depleted wells is no always a feasible option and the aforementioned alternatives have to be implemented. The design and planning of an effective water management strategy is site dependent and is driven by, among other factors, availability of injection wells, disposal costs, treatment cost, local regulation, and blending compatibility in fracking operations.

\subsubsection{Public perception}

Shale gas development faces both positive and negative perceptions worldwide [9194]. Job creation and growth of local economies are perceived as benefits associated with the deployment of shale gas, while impacts on water sources and increased road traffic are 
perceived as risks [94,95]. In general, there are mixed levels of awareness in the United States and Canada [91,94], while greater awareness of potential environmental and social impacts rather than economic benefits is observed in UK [92]. Moreover, it was found that awareness varies geographically, i.e. at national, regional, and local levels, and it tends to intensify in regions where shale gas has been developed [94]. Ethical questions and lack of transparency are issues that have been brought up. Moreover, it has been argued that the influence of communities on decisions related to shale gas development in their regions is minimal or non-existent, which raises concerns about lack of social justice and procedural fairness [96]. Therefore, public perception represents a crucial aspect for the worldwide exploitation of shale gas resources, since licenses to operate should include active community engagement. Lastly, it has been recognized that an effective shale gas governance [96-99] is critical for risk mitigation and public engagement $[96,98,99]$, which could reduce conflicts with local communities.

\subsubsection{Shale gas supply chains}

The methods required for producing shale gas make the exploitation of these resources highly dependent, among other factors, on spot market prices and water resources. Therefore, flexibility, robustness, and efficiency are crucial elements that must be considered in the design, planning, and operation of the shale gas supply chains. This requires integration of the decisions regarding the exploration, production, transportation and processing of these unconventional resources with the corresponding water management decisions within a comprehensive decision-support framework. In this section we review the various elements that must be considered in the design and planning of shale gas supply chains which will be the basis of a series of case studies designed to investigate their interplay at local scales.

A thorough characterization of the prospective shale basin is critical for a successful exploitation of these resources; this entails: (1) geochemical characterization, which defines the potential of a formation to contain fossil fuels, (2) sedimentology characterization, which describes the lithology of the different formations of the reservoir,

(3) characterization of the fracture network system in order to estimate the orientation of the natural fractures, and properties such as fracture aperture and fracture conductivity, 
(4) petrophysical characterization, required to estimate properties of the formations such as absolute and relative permeability, porosity, net pay thickness and depth, pressure and temperature, (5) fluid characterization in terms of the composition, viscosity, sweetness and condensable hydrocarbons, and (6) geomechanical characterization, necessary to study the state of stress of the reservoir, wellbore stability, and rock strength; which are crucial factors for successful drilling and fracturing operations [4,5]. The geological characterization is the basis for assessing the productivity of a shale gas reservoir. This task could be carried out using specialized reservoir simulation tools [100] that allow the integration of geological information along with technical aspects regarding the design of horizontal wells to predict the impact on the production profile. In recent years, advances in horizontal drilling and fracturing techniques have made it possible to drill multiple horizontal wells in a well-pad configuration, reducing water trucking costs, drilling times and associated costs, and impact on land utilization. In a previous work [11], three key well-pad design parameters were identified to have the major impact on gas production: (1) number of wells, (2) horizontal length, and (3) spacing of fracture stages. These parameters, along with petrophysical properties of the reservoir, define not only the gas production profiles of a well-pad but also the water quantity necessary to drill and execute the hydraulic fracturing processes. In general, it can be said that under the same geological conditions, increasing the productivity of a well-pad requires higher water demand so that a wider area of the shale play can be stimulated.

The design of the gas supply chain involves the construction of the gas pipeline network, which involves selection of capacity of pipelines, and locations and capacities of compressor stations, for transporting raw gas from productive well-pads to processing facilities. Location and capacity of processing facilities must be also considered as important decision variables. The design of the water supply chain involves the procurement of fresh water sources, distribution of water for fracking operations, and the handling of flowback and produced water (wastewater). Water availability and water quality are two important aspects regarding the procurement of fresh water. Moreover, the distribution of water refers to selection and sizing of water transportation modes from water sources to well-pads and the allocation and capacity of water storage tanks. 
Wastewater, either the flowback water-fracturing fluid that returns to the surface during the first or second week after fracturing- or produced water -water from the formation that is produced at the surface, can be treated for re-use (using primary treatment), recycling (using both primary and secondary treatment), or disposal (deep injection or environmental discharge). Important aspects in water management are the technical specifications regarding the composition of the fracturing fluids as well as quality regulations for environmental discharge, which are defined by the regional or national regulatory bodies.

The main economic factors involved in the development of shale gas supply chains are capital expenditures, operational expenditures, royalties, and taxes. The development of shale gas resources is largely dominated by capital expenditures, which at the early stages of a project, are mainly related to drilling and fracturing operations. This trend is shifted at later stages of a project in which investments related to infrastructure for treatment of gas and wastewater, and transportation of raw gas and final products are the main component [101]. Operational costs are a small fraction of the total costs, and can be exceeded by taxes and royalties which have been reported to represent as high as $20 \%$ of the total costs [13]. Certainly, taxes and royalties can serve as policy tools for governments to promote the development of shale gas resources, as has been the case, for example, in Mexico, Canada, and China [98,102]. A summary of the various types of input data required in conducting a shale gas supply chain study is presented in Table 1. Specific values of these input parameters which will be used in the case studies reported in Section 4.1 are also shown in the table. Numerical data regarding reservoir characterization has been chosen to represent a shale play in Colombia. Likewise, capital and operating costs of gas and water plants has been adjusted to the Colombian context.

Table 1. Classification of input data for case studies

\begin{tabular}{|c|c|c|c|c|}
\hline & Parameter & Value & Unit & References \\
\hline \multirow{6}{*}{ 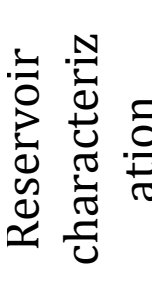 } & Formation depth, $D$ & 9000 & $\mathrm{ft}$ & [11] \\
\hline & Net pay, $h$ & 150 & $\mathrm{ft}$ & [11] \\
\hline & Rock density, $\rho_{r}$ & 156 & $\mathrm{lb} / \mathrm{ft} 3$ & [11] \\
\hline & Initial pressure, $P$ & 6480 & psi & [11] \\
\hline & Bottom Hole Pressure (BHP), $P_{w}$ & 3240 & psi & [11] \\
\hline & Reservoir temperature, $T$ & 200 & ${ }^{\circ} \mathrm{F}$ & [11] \\
\hline
\end{tabular}


Water saturation, $S_{w}$

Gas saturation, $S_{g}$

Matrix Porosity, $\phi_{m}$

Matrix Permeability, $K_{m, i}, K_{m, \mathrm{j}}, K_{m, \mathrm{k}}$

Hydraulic fracture width, $W_{f}$

Hydraulic fracture permeability, $K_{f}^{h y}$

Fracture conductivity, $F_{c}$

Hydraulic fracture half length, $X_{f}$

$\begin{array}{cc}30 & \% \\ 70 & \% \\ 8 & \% \\ \left(5^{*} 10^{-4}, 5^{*} 10^{-4}, 5^{*} 10^{-}\right. & \mathrm{md} \\ 5) & \mathrm{ft} \\ 0.008 & \mathrm{md} \\ 6000 & \mathrm{md}-\mathrm{ft} \\ 48 & \mathrm{ft} \\ 350 & \mathrm{C}\end{array}$

[11]

\begin{tabular}{|c|c|c|c|c|c|}
\hline ס & \multicolumn{2}{|c|}{$\begin{array}{l}\text { Number of wells per well-pad } \\
\text { Horizontal length } \\
\text { Number of fracturing stages }\end{array}$} & $\begin{array}{c}6 \text { and } 14 \\
5000 \text { and } 1000 \\
25 \text { and } 90\end{array}$ & $\begin{array}{l}- \\
\mathrm{ft} \\
-\end{array}$ & $\begin{array}{l}{[11]} \\
{[11]} \\
{[11]}\end{array}$ \\
\hline \multirow{5}{*}{ 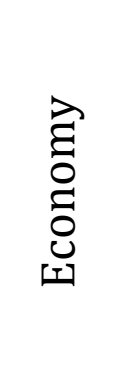 } & \multicolumn{2}{|l|}{ Gas price } & $4000-8400$ & \$/MMSCFD & {$[13,103]$} \\
\hline & \multicolumn{2}{|l|}{ Ethane } & 8400 & \$/MM SCFD & {$[13,103]$} \\
\hline & \multicolumn{2}{|l|}{ Royalties } & 8 & $\%$ & $\begin{array}{c}\text { Assumed } \\
\text { average }\end{array}$ \\
\hline & \multicolumn{2}{|l|}{ Taxes } & 35 & $\%$ & $\begin{array}{c}\text { Assumed } \\
\text { average }\end{array}$ \\
\hline & \multicolumn{2}{|l|}{ Discount rate } & 12 & \%/year & $\begin{array}{l}\text { Assumed } \\
\text { average }\end{array}$ \\
\hline \multirow{14}{*}{ 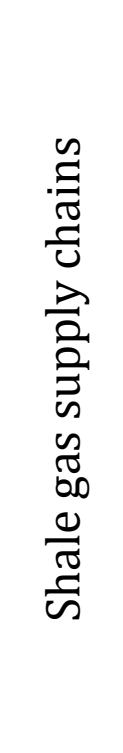 } & \multirow{3}{*}{ Gas plants } & Capacity & $100-350$ & MMSCFD & [13] \\
\hline & & Capex & $442-758$ & Million \$ & [13] \\
\hline & & Opex & 142 & \$/MMSCF & [13] \\
\hline & \multirow{3}{*}{ Water plants } & Capacity & $94,500-441,000$ & gallon/day & [13] \\
\hline & & Capex & $0.3-1.1$ & Million \$ & [13] \\
\hline & & Opex & $0.02-0.03$ & \$/gallon & [13] \\
\hline & \multirow{3}{*}{ Compressors } & Capacity & $150-300$ & MMSCFD & [13] \\
\hline & & Capex & $0.16-0.27$ & Million \$ & [13] \\
\hline & & Opex & 36.9 & \$/MMSCF & {$[13]$} \\
\hline & \multirow{3}{*}{ Gas composition } & Methane & 75 & $\%$ & [13] \\
\hline & & $\mathrm{C}_{2+}$ & 22 & $\%$ & [13] \\
\hline & & $\mathrm{CO}_{2}$ and $\mathrm{N}_{2}$ & 3 & $\%$ & [13] \\
\hline & \multirow{2}{*}{\multicolumn{2}{|c|}{$\begin{array}{l}\text { TDS in waste water } \\
\text { Estimated Ultimate Recovery (EUR) }\end{array}$}} & $34,300-106,700$ & $\mathrm{mg} / \mathrm{L}$ & [13] \\
\hline & & & $24-105$ & bscf & [13] \\
\hline
\end{tabular}

\subsection{Summary of existing challenges and opportunities}

Despite the economic success of shale gas in the United States, the development of these resources is still facing important challenges that can potentially deter their 
exploitation at a global scale. In light of the previous review, we have identified 6 main challenges that call for cooperation between governments, the private sector, local communities, and the scientific community: (1) Market conditions: Since drilling campaigns are highly capital intensive and production lifespans are relatively short, shale gas development is critically dependent on favorable market conditions. The recently observed rapid response of developers to reduce exploration and drilling in the light of price drops illustrates this vividly. (2) Water availability: Access to fresh water sources is crucial for the exploitation of shale gas resources. However, many of the prospective areas are located in regions of high water scarcity. (3) Contaminated water production: A robust wastewater management strategy is essential to avoid contamination of surface or ground water sources and reduce freshwater withdrawals. (4) Environmental impacts: The debate regarding shale gas as a "greener" replacement for coal is still unresolved. The scientific community is devoting great efforts in developing quantitative methodologies to shed light on this topic. (5) Supply chain complexity: Shale gas supply chains involve technical, operational, and strategic decisions that are highly interrelated which can make their design challenging. (6) Poor public perception: Concerns continue to be raised regarding the effects of fracking on environment and public health, largely independent of the specific context of the development in question. In some cases, strong public opposition has resulted in blanket moratoriums or bans of shale-related operations.

Some of these challenges can be tackled if a comprehensive systems-level approach is employed in which the most critical decisions are addressed and evaluated in an integrated fashion. Accordingly, we have implemented mathematical modelling and optimization techniques to develop a decision-support tool to simultaneously investigate aspects of challenges (1), (2), (3), and (5). In this study, we systematically analyze challenge (1) examining the impact of economies of scale. Challenges (2) and (3) are addressed through the analysis of the water-energy nexus in the development of shale gas resources. The analysis makes use of a set of case studies carried out using a decision-supporting tool developed by the authors $[11,13]$. The case studies consider different options regarding the configuration of the well pads, transportation and processing infrastructure from well-pad locations to deliver nodes and from well-pad locations to disposal sites for gas and water, 
respectively. Moreover, the decision-support tool simultaneously addresses the strategic design and planning of drilling and fracturing operations as well as gas and water supply chains via maximizing the corresponding net present value (NPV) using mathematical programming approaches. However, the decision-support tool does not consider secondary recovery and well-pad shut-in operations, which can be relevant from an operational viewpoint. Further details, including features, capabilities, and assumptions, regarding the decision-support tool and the case studies are provided in the following section.

\section{Methods}

Some of the challenges identified in the previous sections are investigated through the implementation of an optimization-based framework that addresses the design and planning of integrated shale gas and water supply chains. The proposed model accounts for strategic and operational decisions and allows for a holistic assessment of shale gas developments. An instance of the model presented in a previous study [13] was implemented in this study. The model corresponds to a Mixed-Integer Linear Programming (MILP) problem. A summary of the mathematical formulation and the main features of the MILP model are presented in the following sections.

\subsection{Model formulation: Key aspects}

The model seeks the maximization of the total profit, represented by the net present value (NPV), of a shale development, as described by Equation 1.

$$
\max N p v=\sum_{t} \frac{\text { CashFlow }_{t}-\text { Capex }_{t}}{(1+\text { ir })^{t-1}}
$$

The scalar ir is the annual interest rate. The cash flow, CashFlow ${ }_{t}$, is calculated as profit before taxes,Profit ${ }_{t}$, plus the depreciation- calculated as a linear function of the depreciation rate, Dep $_{t, t}$, and capital expenditures, Capex ${ }_{t}$, minus applicable taxes, Taxes $_{t}$, as shown in Equation 2.

$$
\text { CashFlow }_{t}=\text { Pofit }_{t}+\sum_{t^{\prime}} \text { Dep }_{t^{\prime} t} * \text { Capex }_{t}-\text { Taxes }_{t}
$$


Total capital expenditures are estimated considering investments on six components: investments in well-pads drilling and hydraulic fracturing, CapexWell, infrastructure for transportation of raw gas, CapexPipe , $_{t}$ installation of compressor stations, CapexComp, water treatment plants commissioning, CapexWatPlants, ${ }_{t}$, gas processing plants commissioning, CapexGasPlants ${ }_{t}$, and infrastructure for final products transportation, CapexProdPipe , $_{\text {, as shown in Equation } 3 .}$

$$
\begin{gathered}
\text { Capex }_{t}=\text { CapexWell }_{t}+\text { CapexPipe }_{t}+\text { CapexComp }_{t}+\text { CapexWatPlants }_{t} \\
+ \text { CapexGasPlants }_{t}+\text { CapexProdPipe }_{t}
\end{gathered}
$$

The profit for each time period, Profit $_{t}$ is calculated as the revenue due to sales of final products, (methane and ethane), and condensates, ( $\mathrm{C}_{3+}$ hydrocarbons), Revenue ${ }_{t}$, minus royalties, Royalties $_{t}$, water transportation cost, WaterTransCost ${ }_{t}$, operational expenditures, Opex $_{t}$, and depreciation, as shown in Equation 4.

$$
\text { Profit }_{t}=\text { Revenue }_{t}-\text { Royalties }_{t}-\text { WaterTransCost }_{t}-\text { Opex }_{t}+\sum_{t^{\prime}} \text { Dep }_{t^{\prime} t} \text { Capex }_{t^{\prime}} \quad 4
$$

Moreover, the taxation charge is defined as the tax rate, times the profit. In this study we consider that taxes are applicable only if profit is positive. This condition is enforced by Equations 5 and 6 .

$$
\begin{gathered}
\text { Taxes }_{t} \geq t x * \text { Profit }_{t} \\
\text { Taxes }_{t} \geq 0
\end{gathered}
$$

The revenue is equal to the sales of final products and condensates to markets, as stated in Equation 7. Condensates sales are represented by variable RevenueC $3_{t}$ which corresponds to the income from selling $\mathrm{C}_{3+}$ hydrocarbons at gas processing plant locations. The terms Price $_{i j t}$ and Prod $_{i j t}$ denote the prices and the flows of final products, respectively.

$$
\text { Revenue }_{t}=\sum_{i j} \text { Price }_{i j t} * \text { Prod }_{i j t}+\text { RevenueC }_{t}
$$


In addition to taxes, royalties are payments to resource owners for the permission to explore and exploit the resources found in their lands. This is modeled via Equation 8, where scalar roy represents the royalty rate.

$$
\text { Royalties }_{t}=\text { roy } * \text { Revenue }_{t}
$$

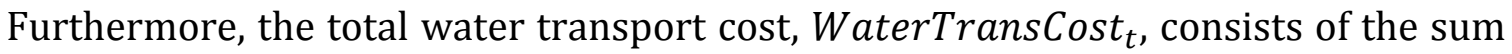
of the cost of transportation of freshwater from water suppliers to well-pads, TransFreshWater $_{t}$, the cost of wastewater transportation from well-pads to water

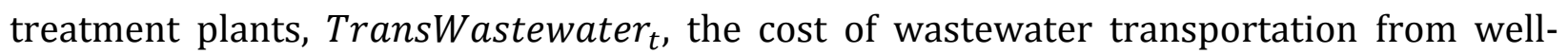

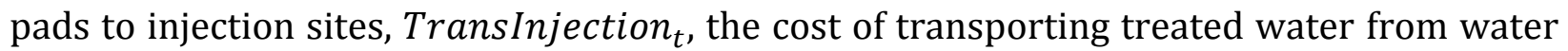
treatment plants to new drilling sites, TransTreatedWater ${ }_{t}$, and the cost of transporting

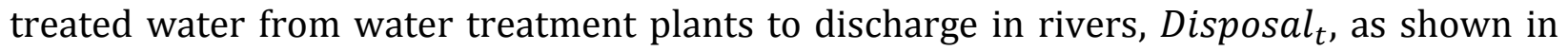
Equation 9.

WaterTransCost

$$
\begin{aligned}
& =\text { TransFreshWater }_{t}+\text { TransWastewater }_{t}+\text { TransInjection }_{t} \\
& + \text { TransTreatedWater }_{t}+\text { TransDisposal }_{t}
\end{aligned}
$$

Similar to capital expenditures, six contributing factors are considered for the calculation of operating expenditures, $O p e x_{t}$. These are: annual cost of well-pads operation,

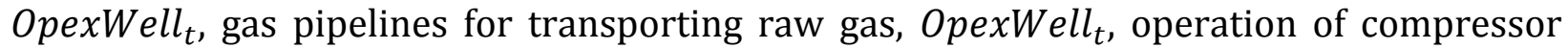
stations, OpexComp , operation of water treatment plants, OpexWatPlants $_{t}$, operation of

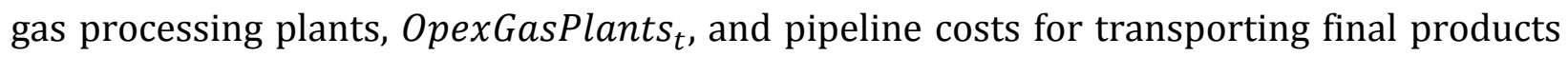

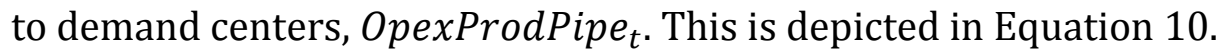

$$
\begin{gathered}
\text { Opex }_{t}=\text { OpexWell }_{t}+\text { OpexWell }_{t}+\text { OpexComp }_{t}+\text { OpexWatPlants }_{t} \\
+ \text { OpexGasPlant }_{t}+\text { OpexProdPipe }_{t}
\end{gathered}
$$

Finally, a constraint on investments is imposed so that capital expenditures do not exceed the maximum capital budget that is available for investment on shale gas projects.

$$
\sum_{t} \frac{\text { Capex }_{t}}{(1+i r)^{t-1}} \leq \text { Budget }
$$


A key decision in shale gas developments is related to the installation and design of well-pads. These decisions affect the productivity of each well-pad and therefore the production of the entire field. This condition is modeled through Equation 12.

$$
\text { ShaleProd }_{w t}=\sum_{d} \sum_{t^{\prime}<t-1} \text { WellGas }_{d w t^{\prime}} * \text { WellDes }_{d, w, t-t \prime}
$$

Where ShaleProd ${ }_{w t}$ corresponds to the raw gas production of each installed wellpad. A binary variable, WellDes $_{d, w, t-t}$, is used in order to decide the design, $d$, and time in which a well-pad must be drilled and fractured. The mathematical formulation of the MILP model involves additional continuous and binary variables as well as equations used to model freshwater supply, well-pads, transportation of raw gas, water, and final products, water treatment plants, gas processing plants, supply of final products and water disposal. Additional information concerning the formulation of the MILP model is provided in previous study [13].

\subsection{Summary of main parameters, variables, and constraints of the model}

A description of the aspects considered in the mathematical formulation are summarized in Table 2 .

Table 2. Summary of the features of the implemented mathematical model

\begin{tabular}{ll}
\hline $\begin{array}{l}\text { Supply chain element } \\
\text { Freshwater supply } \\
\text { Availability }\end{array}$ & $\begin{array}{l}\text { Description } \\
\text { The availability of freshwater for drilling and fracturing operations is } \\
\text { flow, and downstream water demand }\end{array}$ \\
$\begin{array}{l}\text { Acquisition and } \\
\text { transportation cost }\end{array}$ & $\begin{array}{l}\text { Acquisition and transportation costs are calculated based on the } \\
\text { amount of water used and the distance from water sources to well- } \\
\text { pads }\end{array}$ \\
Well-pads & $\begin{array}{l}\text { The design and timing for installation of each well-pad is subject to } \\
\text { optimization. A binary variable is used to model these decisions. } \\
\text { installation } \\
\text { Shale gas production }\end{array}$ \\
$\begin{array}{l}\text { Different gas production profiles are estimated according to the } \\
\text { possible well-pad designs considered in the study. The production } \\
\text { profiles are selected based on the activation of the binary variable } \\
\text { related to well-pad designs. In addition, a cap on the number of wells } \\
\text { drilled per time period is also enforced. }\end{array}$ \\
$\begin{array}{l}\text { A parameter containing the raw gas composition is calculated based on } \\
\text { the properties of the formation under study. The binary variable }\end{array}$ \\
associated with the design of the well-pads is also related to the \\
composition of the raw gas in each well-pad.
\end{tabular}


Water demand

Water production

Water trans. cost

Capex and Opex

Raw gas transportation Pipeline capacity

Compressor stations

Capex and Opex

Wastewater treatment plants Plant capacity

Material balance

Treated water trans. costs

Capex and Opex

Gas treatment plants Plant capacity

Material balance

Sales
The water required for drilling and fracturing well-pads is considered a function of the well-pad layout. This variable is function of the design of the well-pad. The water demand can be supplied by fresh and/or treated water. Accordingly, a constraint is enforced to meet specifications imposed on the water blend such as maximum allowed concentration of hardness ions like Calcium, Chlorides, Barium and Strontium.

The wastewater production from well-pads is calculated as the sum of flowback water and produced water. The flowback water is calculated as a percentage of the water required to put the well-pad in operation. The wastewater can be sent for treatment and re-used/recycled, for injection, or disposed in rivers.

The cost of trucking wastewater from well-pads to water plants or disposal sites is considered in the model formulation.

The capital expenditures associate with drilling and installing a wellpad are considered. In addition, the operating costs are also estimated using the production of the well-pad as a proxy.

The installation period and capacity of pipelines is considered for transportation of raw gas from well-pads to compressors, compressors to compressors, and well-pads to gas plants. A binary variable is associated with these decisions

The installation and capacity of compressor stations for raw gas transportation is subject to optimization. A binary variable is associated with these decisions.

Capital expenditures and operating costs are calculated based on the installation and operation of compressor stations.

The amount of wastewater that can be processed in a plant is limited by its installed capacity. The capacity of the plant is subject to optimization.

Blending of different wastewater qualities is allowed at the input of the water treatment plant. Limits on the concentration of TDS are imposed on the input stream to ensure that the technology is adequate for treating the stream. In addition, storage of wastewater and treated water is considered.

Transportation costs of treated water due to trucking from water treatment plants to drilling sites is included in the model formulation.

Capital expenditures and operating costs are estimated based on installed capacity and treated wastewater, respectively.

The amount of shale gas that can be processed in a plant is limited by its installed capacity. The capacity of the plant is subject to optimization.

The efficiency in the separation of the different gas fractions is taken into account.

After the separation process, $\mathrm{C} 3+$ hydrocarbons are assumed to be sold at gas processing plant locations. 
Capex and Opex

Products transportation

Pipeline capacity

Capex

Demand supply

Disposal

Wastewater disposal Opex
Capital expenditures and operating costs are estimated based on installed capacity and processed raw gas, respectively.

Methane and Ethane are delivered to customers by pipelines. The capacity of the pipelines is subject to optimization.

The associated capital expenditures for installation of pipelines is estimated based on the capacity of the pipeline.

A constraint on demand is imposed so that the production of final products does not surpass the demand of the region (or country) selected for the case study

The main features and capabilities of the framework are as follows:

- The framework allows off-line coupling of shale gas supply chain design and planning with simulation tools for the estimation of gas production profiles. This feature is particularly useful when experimental production data is not accessible, e.g. during the development of new shale gas plays.

- The framework includes the configurations of the well-pads as a decision element, which defines the gas production profiles as well as water demand for hydraulic fracturing and wastewater production flow rates. Specifically, two configurations are contemplated; one is focused primarily on the economics while the other one is based on the intensity of water use. Water intensity can be used as an environmental criterion.

- Geographic information systems are used to estimate freshwater availability via hydrological balances including downstream demand, infiltration, evapotranspiration, and historical data on precipitation.

- The mathematical formulation includes explicit constraint for blending of water and water quality specification, i.e. constraints on TDS, in fracturing and wastewater treatment operations. The flexibility of the formulation can accommodate temporal and spatial variability of TDS concentration. 
- The design and planning of the gas and water supply chains is addressed simultaneously, which, as illustrated in our results [11,13], is critical to reveal intrinsic synergies and trade-offs between the decision elements involved in the development of shale gas resources.

The major assumptions considered in the mathematical framework are:

- Optimization of mobile water facilities is not addressed.

- GHG and fugitive methane emissions are not evaluated.

- Capacities of compressor stations, water treatment plants, and gas treatment plants are discretized.

- Secondary recovery operations are not considered.

- Well-pad shut-ins are not modelled.

Mathematical modelling and well-established optimization techniques implemented in commercial software GAMS 24.4.1, ArcGIS ${ }^{\circledR}$ 10.2, Aspen Hysys ${ }^{\circledR}$, and Aspen Capital Cost Estimator ${ }^{\circledR}$ were used to carry out the design of the case studies and the optimization process. Further details are presented in the following sections.

\section{Study framework ${ }^{1}$}

\subsection{Scope of case studies}

The infrastructure for the case studies was designed based on the Middle Magdalena Valley Basin, which is a prospective shale play in Colombia. All case studies are based on the same potential infrastructure for gas and water transportation and processing. Three case studies, namely Case A1, Case A2, and Case A3, are evaluated. The total number of potential well-pads is 6,8 , and 10 for Case A1, Case A2, and Case A3, respectively. Additionally, the case studies contemplate two potential well-pad designs.

The potential infrastructure for gas and water supply chain for Case A1 (see Figure 4) were designed in ArcGIS 10.2 as follows: The well-pads denoted as W1 and W4 are connected to the compressor station 1. The well-pads W2 and W3 are connected to the compressor

\footnotetext{
${ }^{1}$ Data set available upon request
} 
station 2. The well-pad W6 can send the produced gas to the compressor station 1 and/or 2. Only the well-pad W5 is connected directly to a gas treatment plant, gas plant 2 in this case. According to geochemistry information of the area, the location of the well-pads coincides with a wet-gas bearing shale formation. After the raw gas is processed, the final products are sent to the demand centers. In this case, we consider as demand centers three injection points located along the National pipeline network in Colombia. The methane fraction produced in gas plant 1 and 2, can be delivered to two different injection points in the southwest or southeast, respectively. These injection points are subsequently connected to several gas-based power plants. Only one common point placed in north of the shale play is included for ethane delivery. This point is indirectly connected to a petrochemical plant. The prices of the final products were based on information from the Colombian Mining and Energy Planning Unit-UPME (http://www1.upme.gov.co/). The fresh water requirements for drilling and fracturing operation in well-pad locations can be supplied from three rivers. River III supplies water to well-pads W1, W2 and W4; river II is the water source for well-pad W3; and river I supplies fresh water to well-pads W5 and W6. The produced water can be sent by truck to any of the two water treatment facilities. Alternatively, the wastewater can also be sent for deep injection into an adequate well located towards the north of the shale play. The treated water can be re-used/recycled and used for drilling and fracturing new well-pads or discharged into rivers I and II. Water trucking is the only transportation mode considered, although additional modes can be included if appropriate. 

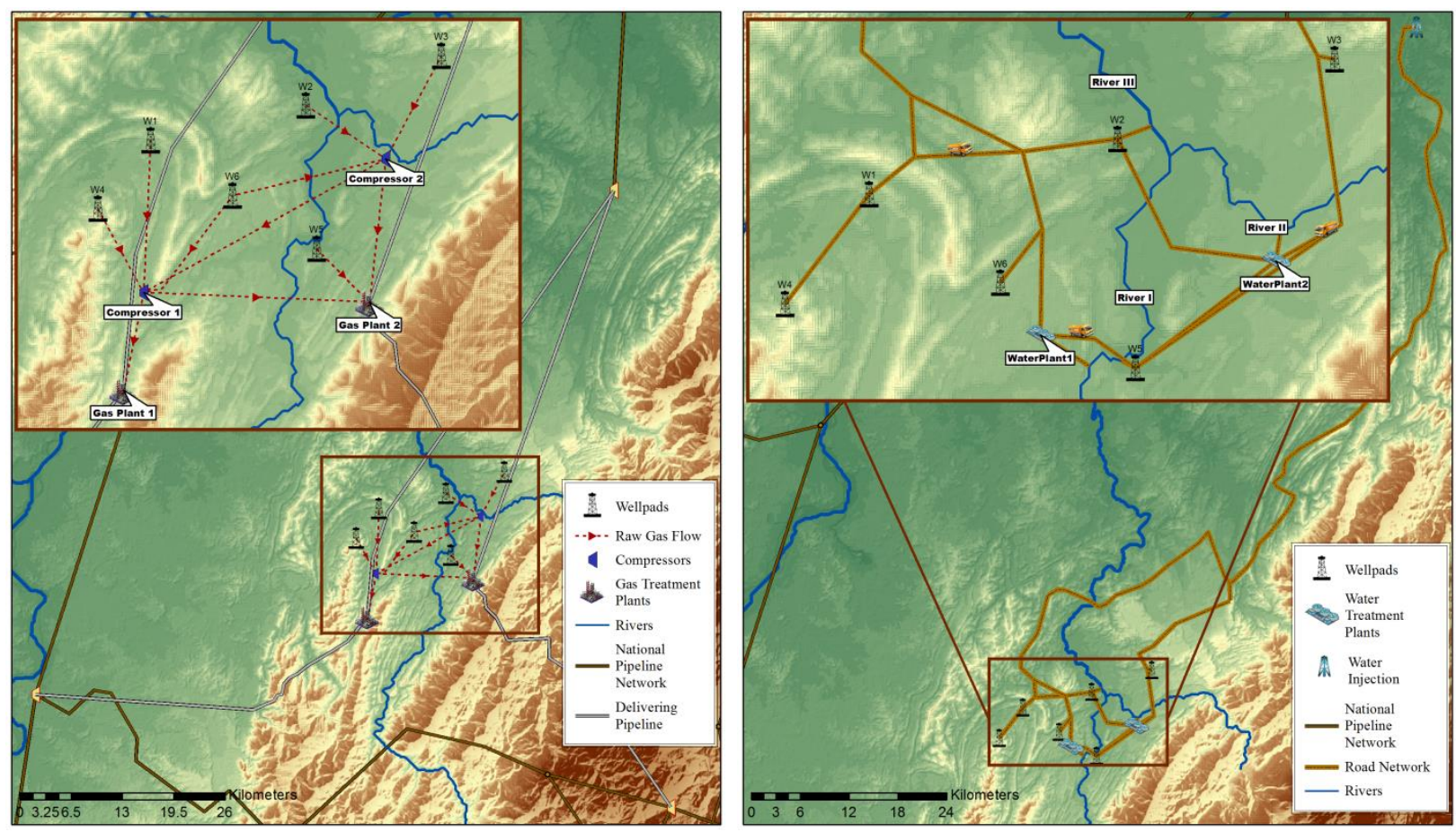

Figure 4. Gas supply chain (Left-hand side) and water supply chain (Right-hand side) for a case study with 6 potential well-pads.

The potential infrastructure for gas and water transportation and processing was based a road network connecting the different water sources with the demand points and the treatment facility locations. Regarding the gas transportation network, the gas pipelines were discretized in three different capacities, where each capacity corresponds to a given commercial diameter depending on the distances between the two connected nodes, for example, the distance between a given well-pad and a given compressor station. The commercial diameters were estimated based on simulations implemented in Aspen Hysys $^{\circledR}$. The total distances for the different pipeline connections were calculated in ArcGIS 10.2 [104]. This information is used to calculate the installation costs. Two compressor capacities of 150 and 300 MMSCFD were included in the case study. The cost information regarding the installation of a compressor in Colombia was supplied by a local company, under confidential agreement. The energy consumption of the compressors, calculated in Aspen Hysys ${ }^{\circledR}$, was the basis for estimating the operational costs. Three capacities of 100 , 200 and 350 MMSCFD were chosen for the gas treatment plants. The installation costs and the operating costs were based on Aspen Hysys ${ }^{\circledR}$, Aspen Capital Cost Estimator ${ }^{\circledR}$, and information provided by local companies in Colombia. 
For the water supply chain, the water transportation costs were calculated based on the road network distances. The rivers I, II and III were assumed to have enough available water to drill and fracture 14 wells in the rainy season, which for the specific area under study corresponds to the third quarter of the year. For the dry season, the first quarter of the year, the available water was estimated to be about $50 \%$ of the available water in the rainy season. For the second and fourth quarter, this percentage was set at $75 \%$. The total dissolved solids (TDS) concentration on water for the rivers I, II and III were set at 130, 150 and $140 \mathrm{mg} / \mathrm{l}$, respectively. The TDS in the produced water was assumed to be different in each well-pad ranging between 34,300 and $106,700 \mathrm{mg} / \mathrm{l}$. The capacities of the water treatment plants were discretized in 94,500, 220,500 and 441,000 gal/day. The water plant 1 operates with primary treatment and can process water with maximum TDS concentration of 50,000 mg/l. The water plant 2 operates with secondary treatment technology which can treat water with TDS concentrations of up to $120,000 \mathrm{mg} / \mathrm{l}$ and produces a treated water stream with TDS concentration of $100 \mathrm{mg} / \mathrm{l}$. The installation and operating costs correspond to the Colombian context and were supplied by local companies under confidential agreement. The maximum discharge flow rate into rivers I and II was set at 40,000 and 200,000 gal/day. For the deep well injection technology, the well capacity is limited up to $336,000 \mathrm{gal} /$ day, with operating costs of $0.75 \mathrm{USD} / \mathrm{gal}$.

The infrastructure for the 6 well-pad case was extended in Case A2 to an 8-well-pad infrastructure by adding two well-pads, W7 and W8, which are connected to the compressor 2 as shown in Figure 5. 

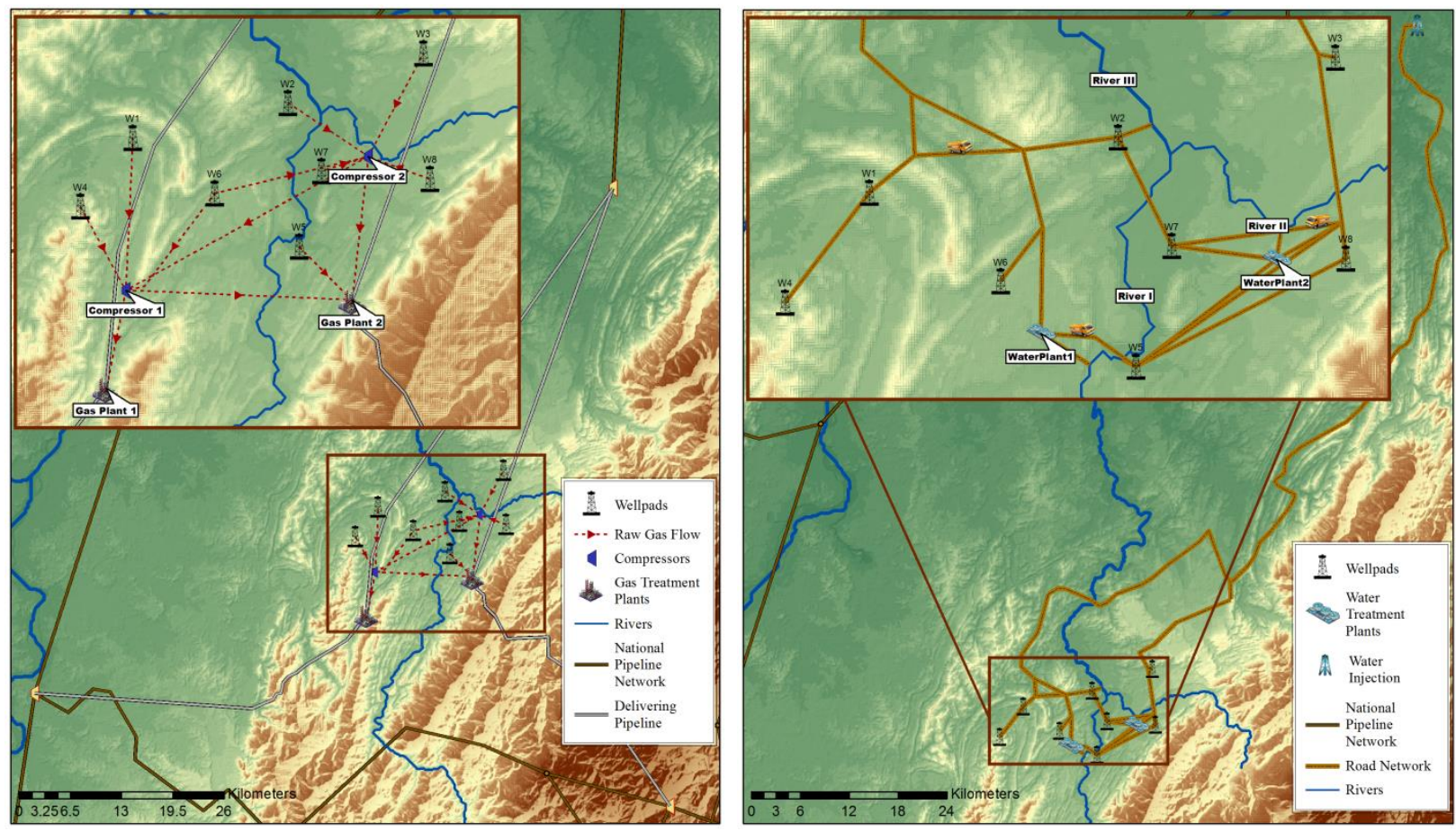

Figure 5. Gas supply chain (Left-hand side) and water supply chain (Right-hand side)

for a case study with 8 potential well-pads.
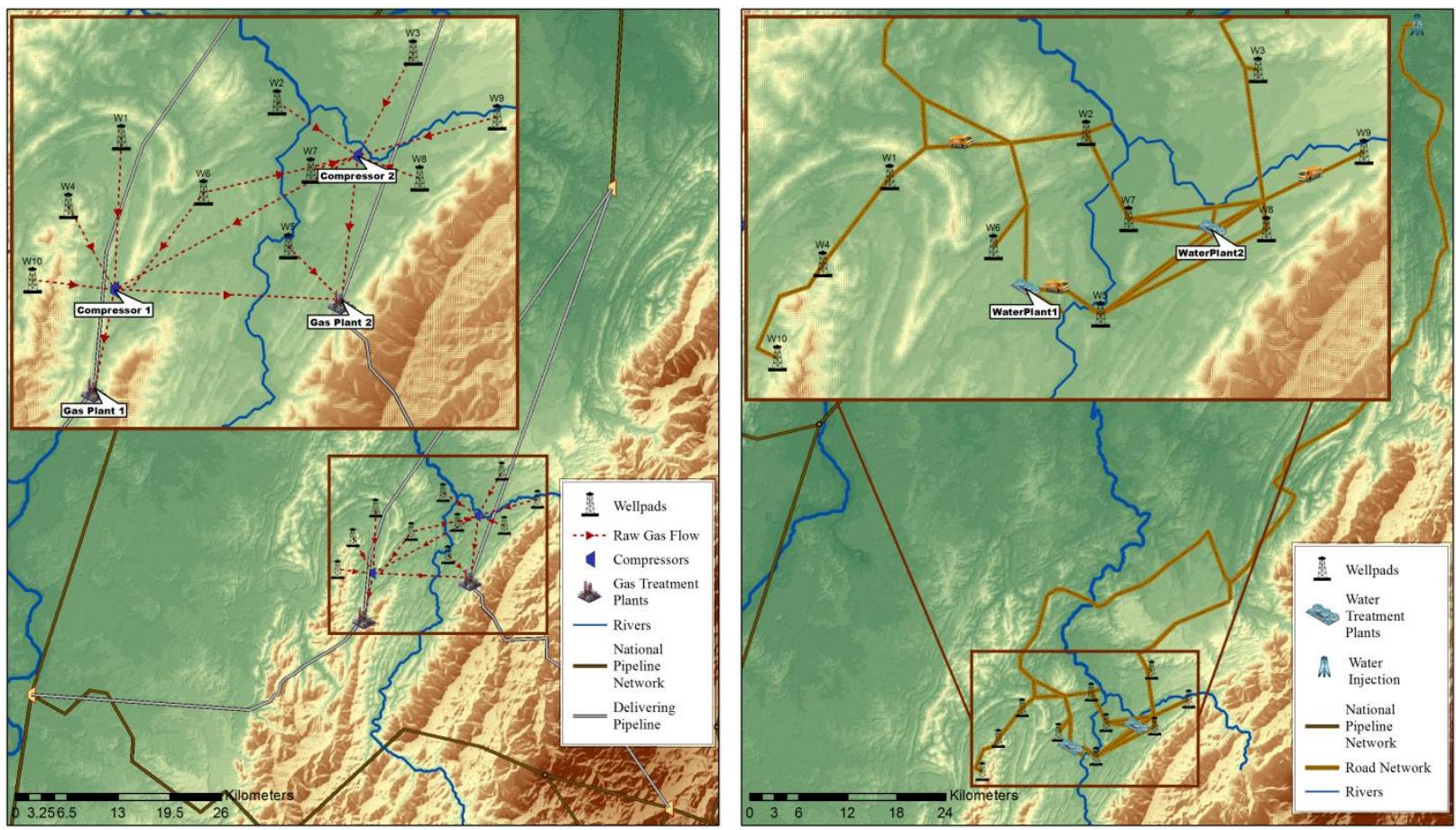

Figure 6. Gas supply chain (Left-hand side) and water supply chain (Right-hand side)

for a case study with 10 potential well-pads. 
The fresh water for the well-pads W7 and W8 is collected from river I and river II, respectively. The wastewater can be disposed into a deep-injection well or sent by truck to be treated in either water plant 1 or 2. The 10-well-pad infrastructure of Case A3 builds upon the previous infrastructure with two new well-pads, W9 and W10 as shown in Figure 6. The well-pad W9 and W10 are connected to compressors 2 and 1, respectively. The source of fresh water for well-pad W9 is river I whereas the water for the well-pad W10 is supplied by river II. The deep-injection technology for disposing the wastewater is available for the new well-pads. We assumed that water plant 1 and 2 can process the wastewater from well-pad W9, and only water plant 1 can process the produced water from well-pad W10.

Finally, the MILP problems were solved using GAMS 24.4.1 with CPLEX 12.6.1 on a server with Dual Intel ${ }^{\circledR}$ Xeon ${ }^{\circledR}$ E5620 @2.4Ghz with 4 Cores and 16 GB RAM running Debian Linux. The optimality gap was set to less or equal to $1 \%$ for all cases. The model statistics for all of the instances are presented in Table 3. As expected, the size of the model increases as the number of well-pads increases.

Table 3. Model statistics and computational results for Cases A1, A2, and A3

\begin{tabular}{lccc}
\hline & \multicolumn{3}{c}{ Instance } \\
\cline { 2 - 4 } & 6 well-pads & 8 well-pads & 10 well-pads \\
\cline { 2 - 4 } Total number of variables & 7,779 & 8,845 & 9,831 \\
$\quad$ Continuous variables & 5,201 & 5,921 & 6,561 \\
$\quad$ Binary variables & 2,578 & 2,924 & 3,270 \\
Total number of constraints & 6,661 & 7,295 & 7,929 \\
Non zero constraint matrix elements & 87,171 & 100,233 & 112,935 \\
CPU time [s] & 123.3 & 518.0 & $6,666.2$ \\
Nodes explored & 34,991 & 151,145 & $2,590,842$ \\
Optimal NPV [Million \$] & 114.26 & 333.47 & 584.39 \\
\hline
\end{tabular}

This increase in the size of the model, especially the increase in the total number of binary variables, has a direct impact on the total number of nodes explored to find a solution that meets the optimality criteria, and therefore on computation times. As observed in Table 3, the number of nodes explored and the CPU time increases exponentially with the number of binary variables. Also, the CPU time increases almost linearly with the total number of nodes that are explored, as expected. 


\subsection{Economies of scale}

Using the input data of Table 1 and the above described supply chain model, three different instances are considered: Case A1, A2 and A3. As described previously, the instances differ in the total number of potential well-pads included in the supply chain, which was set to 6, 8 and 10 for cases A1, A2, and A3, respectively. Additionally, two wellpad designs, MaxNPV - a configuration of 14 horizontal wells that maximizes the NPV of the well-pad- and MinWI - a configuration of 6 horizontal wells that minimizes the water intensity of the well-pad- were considered along with the infrastructure which includes all of the options for gas and water transport and processing. Depending on the well-pad configuration selected for each potential well-pad location, cases A1, A2, and A3 contemplate the installation of up to 84, 112, and 140 wells, respectively. As a reference, a total of 13,450 horizontal wells were reported in the Barnett shale play in 2013. The 10 top operators account for about $83.3 \%$ of the wells, while $5.5 \%$ of the wells were operated by around 120 companies with less than 24 wells each [105]. Moreover, the case studies are designed to investigate the performance of shale gas developments under water-stressed scenarios. As will be shown, the economic benefits of developing a shale gas field can be strongly affected by the scarcity of water sources.

The selected designs for each instance of the MILP model are shown in Figure 7. For the first case, the Case A1, three well-pads (W2, W3 and W5) were drilled and fractured with a MaxNPV design and three well-pads (W1, W4 and W6) with a MinWI design. 


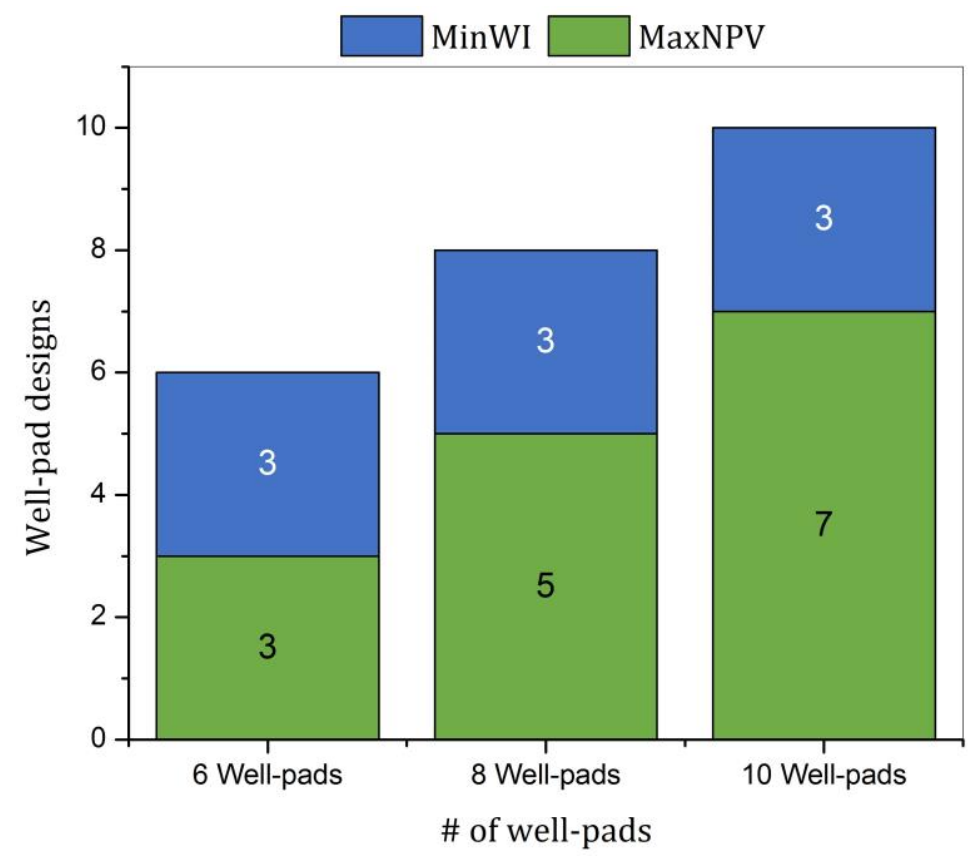

Figure 7. Selected well-pad designs

In the second case, the Case A2, 5 well-pads (W2, W3, W5, W7 and W8) were selected with MaxNPV design and 3 well-pads (W1, W4 and W6) with MinWI design. Finally, for Case A3, 7 well-pads (W2, W3, W5, W7, W8, W9 and W10) were put in operation with MaxNPV design and 3 well-pads (W1, W4 and W6) with MinWI design. In total, for the Case A1, 60 wells were drilled and fractured; for Case A2, a total of 88 wells were put into operation while 116 wells were drilled and fractured in Case A3. The addition of new potential sites for gas production is expected to have an effect in the productivity of the shale play. The variation of the total production of the shale gas field with the number of well-pads is shown in Figure 8. 

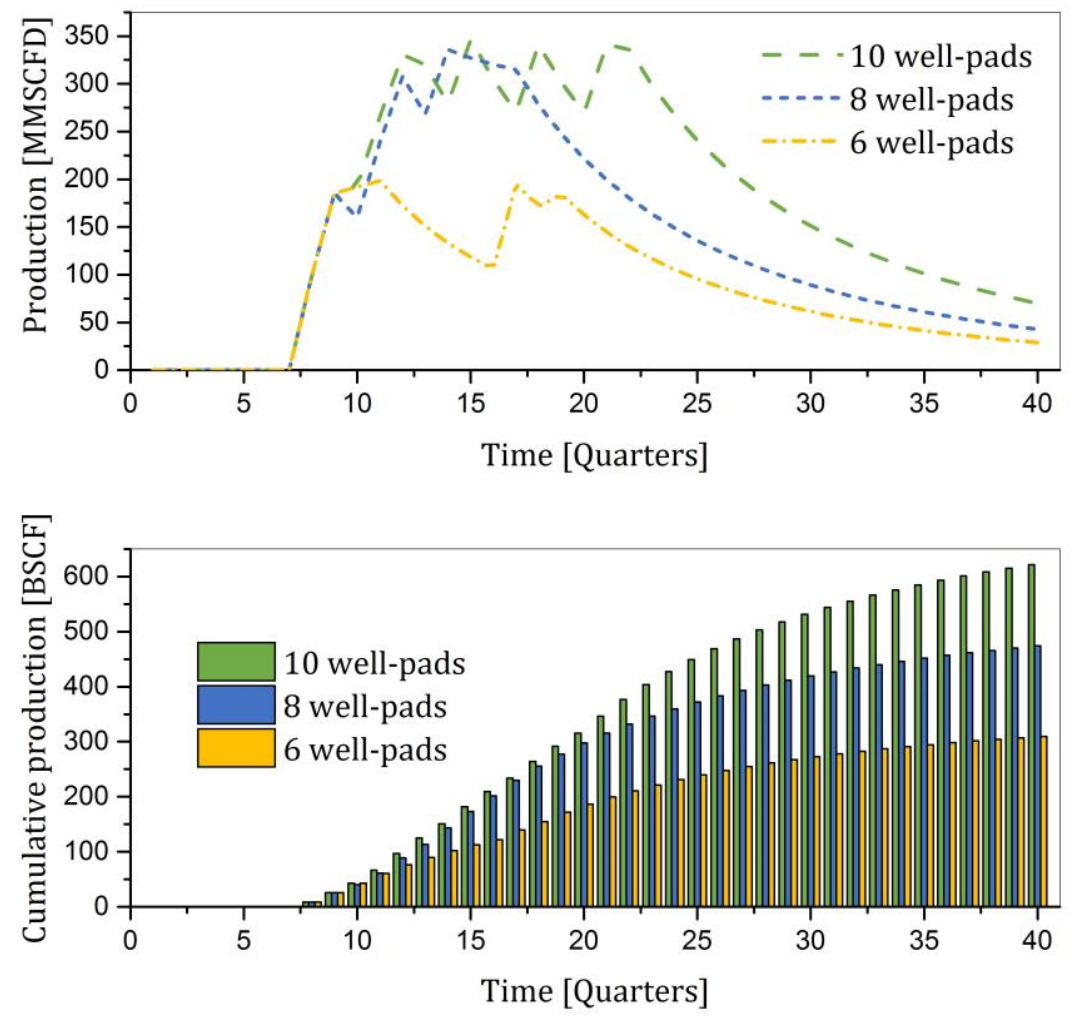

Figure 8. Variation of gas production with number of well-pads

For all three cases the gas production starts off at the same time immediately after period 7. For the first instance (Case A1), four well-pads were drilled consecutively in periods 7, 8, 9 and 10 (see Figure 9) reaching a production peak of 198.6 MMSCFD in period 11; afterward, the total production decreases. 

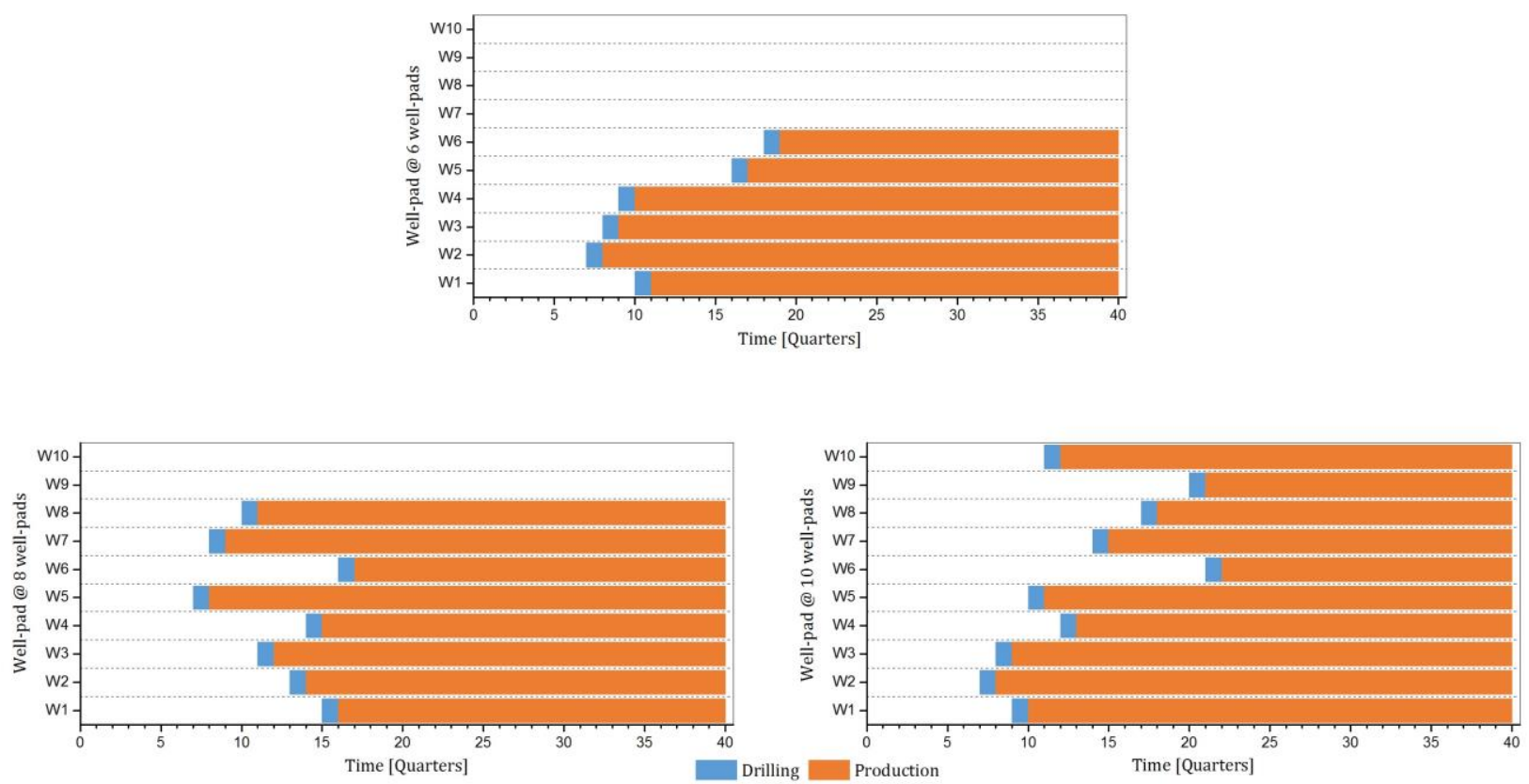

Figure 9. Drilling schedule for Case Study A

The decrease is compensated by activating well-pads W5 and W6 in periods 16 and 18, which is reflected in production peaks of 195.0 MMSCFD and 184.2 MMSCFD in periods 17 and 19, respectively. In the second case, the addition of two new well-pads has a remarkable effect on the total production, causing it to reach its peak in period 14 with 335.6 MMSCFD. However, as the additional well-pads were used to increment the peak production, this could not be maintained for long and the production quickly decreases after period 17. When two additional well-pads are included in the case study, Case A3, it reaches a production plateau similar to the previous case, with a peak of 346.6 MMSCFD in period 15, and it is kept within some limits for almost 10 periods. In this case, instead of surpassing the production of the previous case, it maintains the production level for a longer duration. It can be observed that the drilling schemes tend to achieve a production plateau; in the first two cases this is not easily recognized due to the low number of potential well-pads, however this is evident in the last case. It should be noted that three well-pads (W1, W4, and W6) with MinWI configuration were always selected. The preference for a less water intensive design for well-pads W1, W4, and W6 was found to be associated with a combination of a higher water transportation cost (see Figure 4, Figure 5, and Figure 6) and a higher TDS concentration on wastewater. For instance, wastewater from well-pad W4 has the highest TDS concentration. It is important to note that a less 
water intensive design also translates into lower wastewater production volumes. Therefore, even with a relative higher TDS concentration, the wastewater from a given well-pad can be treated in a water plant with primary technology by dilution with wastewater that has a relative lower TDS concentration but higher production volumes. The reason for the delay of the drilling operations is the higher methane prices at the end of the time horizon, thus the drilling schedule is oriented to compensate for the losses in total production due to the delay, the Estimated Ultimate Recovery (EUR) decreases with the delay of the drilling operations, with higher methane prices at the end of the time horizon. It is noted that when the water plant with primary treatment technology is installed before the water plants with secondary treatment technology, Cases A1 and A3, well-pads with lower TDS concentration on wastewater (W2 and W3) are drilled at the beginning of the schedule, as observed in Figure 9. This strategy allows wastewater treatment and re-use at the beginning of the schedule using primary treatment technologies and then, when well-pads with higher TDC concentration of wastewater are drilled, wastewater treatment with secondary technology can be implemented. In general, there is not a clear pattern for the schedule of the drilling of a specific well-pad, rather the optimal schedule depends more on the configuration of the whole system than on each specific well-pad location.

The optimal NPV's for Cases A1, A2 and A3, obtained were about \$114.26, \$333.47, and $\$ 584.39$ million respectively. It is revealing to normalize the NPV using the total gas production. The normalized NPV for Case A1 was found to be $0.37 \$ / \mathrm{MMBtu}$, while it almost doubles for Case A2 (0.70 \$/MMBtu). Similarly, in case A3, the normalized NPV increases by $0.24 \$ / M M B t u$ to reach a value of $0.94 \$ / M M B t u$. These trends are driven entirely by economy of scale- the cost saving that is obtained by increasing scale of operations. The breakeven time, using as reference the first period with investments, was found to be 6.5 years for Case A1, and 5.5 years for Cases A2 and A3. The values for Capex, Opex (including water transportation cost), royalties and taxes are discounted to the first period and the total cost breakdown are presented in Figure 10a. 

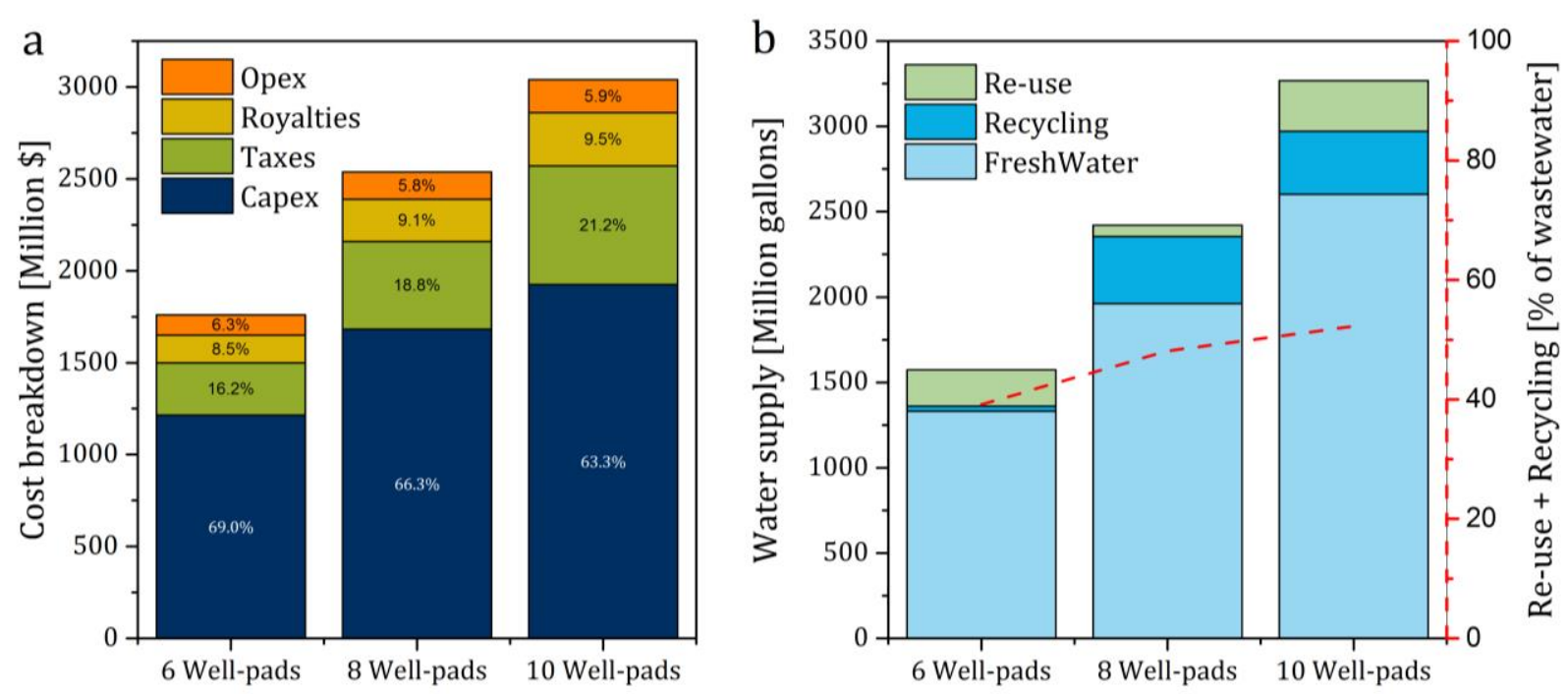

Figure 10. Economics and water management strategy as function of the scale of shale gas development: (a) Cost breakdown and (b) Water management strategy

The Capex share of the total cost decreases as the number of well-pads increases, since a higher number of well-pads allows a more efficient use of the gas and water transportation and processing infrastructure. Moreover, Capex has the highest share, between $63.3 \%$ and $69.0 \%$ of total cost, while the lowest share is associated with operating expenditure, between $5.8 \%$ and $6.3 \%$ of total cost. These results reaffirm the fact that oil and gas industry projects are highly capital intensive. Total royalty and tax payments increase as the number of well-pads increases, since they depend on total gas production, which is related to the number of well-pads. The breakeven gas price, defined here as the ratio of total expenditures (Capex plus Opex) divided by total gas production, decreases as the number of well-pads increases. The breakeven gas price was estimated to be $4.28,3.86$, and 3.39 \$/ MMBtu for Cases A1, A2 and A3, respectively. This trend is also a consequence of economies of scale. Furthermore, as mentioned previously, it was found that less water intensive configurations are chosen for well-pads in which TDS concentration in wastewater is high, which translates to lower flowrates of poor quality wastewater and therefore a lower treatment cost. Additionally, a parametric analysis for TDS concentration is discussed later in this manuscript.

The water supply mix presented in Figure $10 \mathrm{~b}$ indicates that about 1,573.8 million gallons of water are required for drilling and fracturing operations in Case A1 (6 wellpads). Moreover, this value presents an increment of $63.8 \%$ for Case A2 and almost doubles 
in Case A3. On a normalized basis using total gas production in energy units, water consumption was about 4.30, 4.01, and 4.18 gallon/MMBtu for Cases A1, A2 and A3, respectively. These values are well within the range, i.e. from 3.63 to 10.32 gallon/MMBtu, of life cycle water consumption for U.S. shale plays previously mentioned in this study. However, the share of fresh water on the mix was found to be $84.63 \%, 81.11 \%$, and $79.64 \%$ for Cases A1, A2 and A3, respectively. Larger scales allow more efficient usage of fresh water resources, for instance, the water intensity in terms of freshwater withdrawal per unit of produced energy for Case A2 and Case A3 is $~ 3.7 \%$ and $\sim 2.7 \%$ lower than that of Case A1, respectively. Concerning the water management strategy, from Figure 10b it can be seen that total wastewater treated for re-use or recycling increases as the number of well-pads increases. For example, water re-used -wastewater treated using primary technology- or recycled -wastewater treated using secondary technology- was found to be $39.12 \%, 48.15 \%$, and $52.26 \%$ of total wastewater for Cases A1, A2 and A3, respectively. This increase in water re-use and recycling is a result of increasing the total number of well-pads which adds more flexibility to the wastewater management, increasing options for re-use and recycling. It can be inferred from the previous results that increasing the scale of operations of the shale gas development, i.e. the number of wells and well-pads, translates not only into a better economic performance but also into a higher total fresh water withdrawal, which increases the stress on water sources.

\subsection{Water-Energy-Economy of scale nexus}

High water withdrawal and consumption is one of the major concerns regarding the production of shale gas. On the other hand, the forecast of water availability is subject to uncertainty due mainly to climate and weather variability. The analysis of the waterenergy-economy of scale nexus in the context of shale gas development identifies synergies between water availability, the configuration of the well-pad, the water management strategy, and the economics of the shale gas development. Thus, a deeper understanding of the repercussions of water availability on the design of the shale gas supply chain is warranted. This goal is addressed, next, by means of a parametric analysis based on the amount of water available at the fresh water sources. The infrastructures for the three cases presented previously will be used to carry out the analysis. The parametric analysis 
involves the systematic reduction of the fresh water by $10 \%$ increments, until $50 \%$ of the initial water availability is reached. The analysis is based on the aforementioned case studies (Case A1, Case A2, and Case A3).

For the base case $(100 \%$ water availability) of Case A3, the initial investment was made in the fourth period, the breakeven point of the project was reached after 22 periods (5.5 years) and the final NPV is $\$ 584.4$ million. When the water availability was reduced by $10 \%$ (90\% Water availability) the NPV drops to $\$ 499.6$ million, which is a reduction of $14.5 \%$ compared to the base case. A further reduction of $20 \%$ of fresh water (80\% water availability) causes the breakeven time to increase to 6 years after the initial investment. The NPV is substantially reduced to $\$ 332.4$ million; $43.1 \%$ with respect to the base case. For the $70 \%$ Water available case, the project achieves a profit after 31 periods $(7.75$ years) of the initial investment. The NPV of the project is $\$ 218.1$ million, which corresponds to a reduction of $62.7 \%$ from the base case. For $40 \%$ and $50 \%$ of water reduction ( $60 \%$ and $50 \%$ water available cases), the breakeven time is 7 years. The NPV for both projects is $\$ 148.3$ and $\$ 78.1$ million, respectively. These NPVs correspond to a reduction of $74.6 \%$ and $68.6 \%$ from the base case for $60 \%$ and $50 \%$ of water availability, respectively. The total cost breakdown for the six scenarios is depicted in Figure 11. The total cost decreased from $\$ 3,039.2$ million for the base case to $\$ 1,575.5$ million for the case with $50 \%$ reduction of water availability, which is around $48.2 \%$ decrease in expenses. 


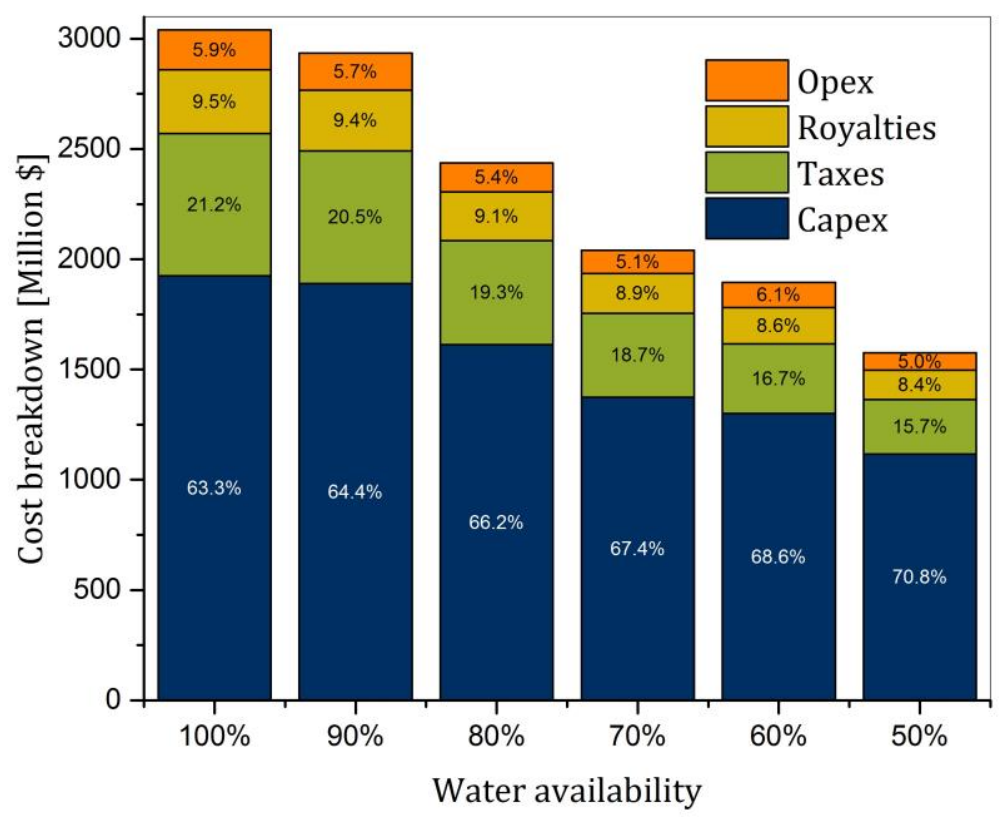

Figure 11. Cost breakdown for Case A3

The breakeven price varies from 3.39 \$/MMBtu to 4.28 \$/MMBtu for the cases with $100 \%$ and $50 \%$ water availability, respectively. This limitation on fresh water availability is reflected in an increment of $26.4 \%$ of the gas breakeven price. These trends suggest a sustained decline in the production, transportation and processing of raw gas. The drop in gas production is evidenced by the tendency for selecting less intensive water designs as the limitations of fresh water become critical. The well-pad designs selected for every case are summarized in Figure 12. Initially, 7 well-pads were installed with MaxNPV configuration, and 3 well-pads with MinWI configuration. 


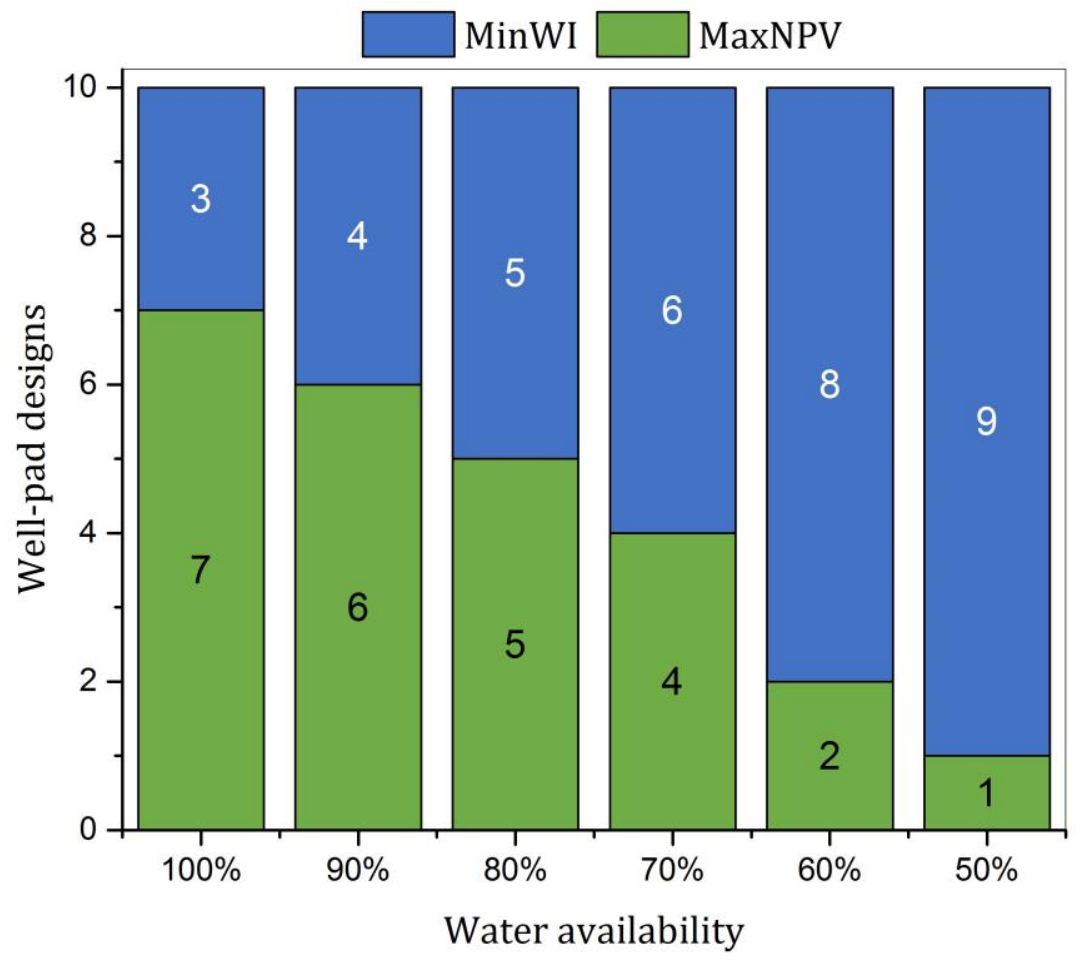

Figure 12. Selected well-pad designs for Case A3

For the second case, the configuration of well-pad W10 is shifted from MaxNPV to MinWI. This well-pad is located relatively far from the water sources and from the water treatment facilities; the change of its configuration not only overcomes the limitations of fresh water but also has major impact on reducing the water transportation costs. For the next case, the model opts for a similar decision based on the transportation costs. In this case, the well-pad W3 is drilled and fractured following a MinWI configuration. In the following cases the MinWI designs become predominant. Finally, for the last case only the well-pad W5 has MaxNPV design, as this well-pad is located close to the water source and water treatment facilities, which results in low transportation costs of water. The drilling scheme for the scenarios is presented in Figure 13. 

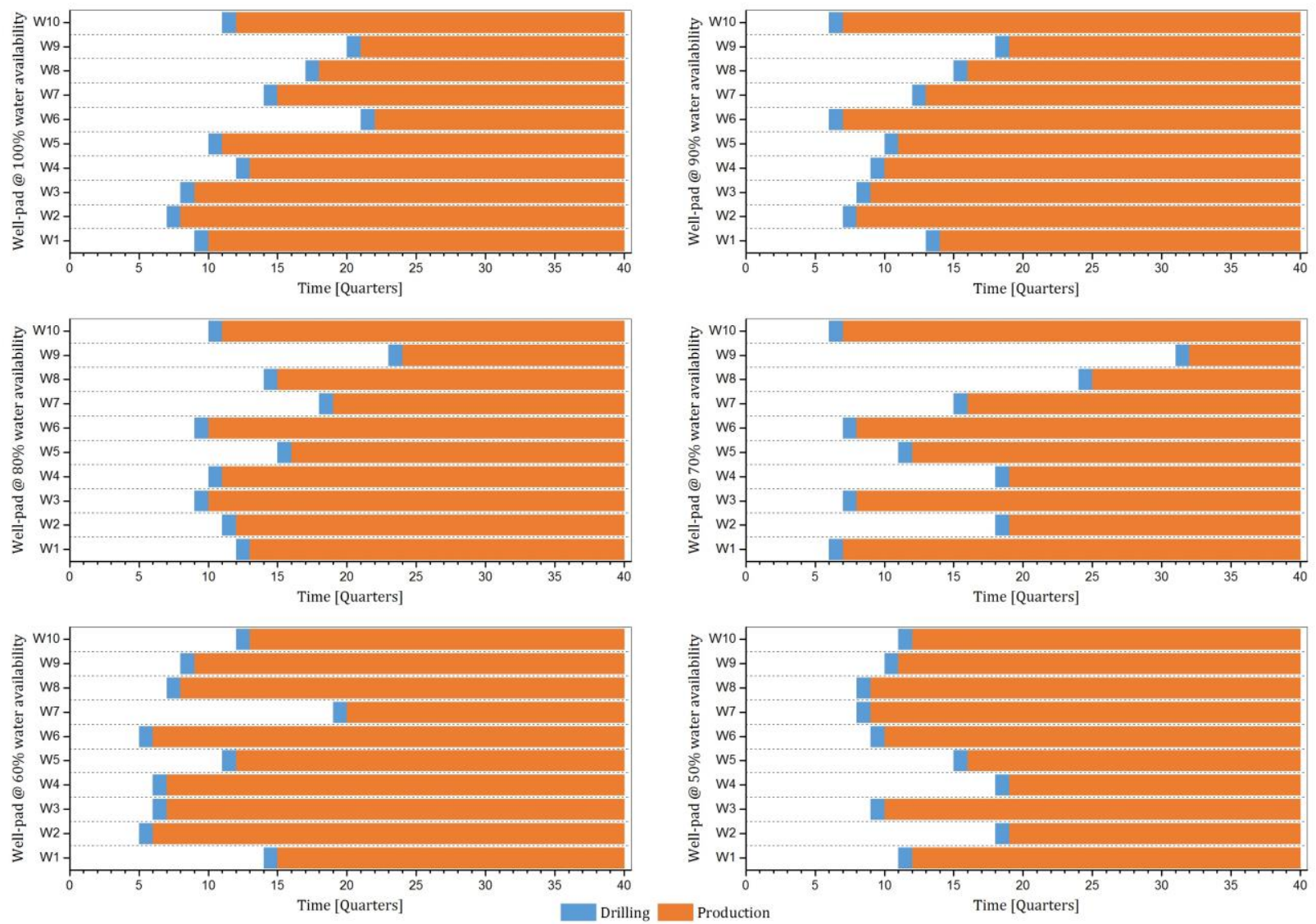

Figure 13. Drilling schedule for Case A3

Initially, only one well-pad per period is drilled, however, as the availability of water decreases and more well-pads with MinWI configuration are selected, it is possible to drill two well-pads in the same period. For example, for the case $90 \%$ water availability, the well-pads W6 and W10 are drilled simultaneously in period 6. For the next case, 80\% water availability, the drilling scheme suggests drilling the well-pads W3 and W6 in period 9 and then W4 and W10 in period 10. Analogous patterns are found for the rest of the cases, although there are not explicit trends in the drilling schedule of the different wellpads. However, there is an interesting tendency in the way pairs of well-pads are chosen to be drilled; they are complementary regarding the TDS concentration of the produced water. In our case study, we set the maximum TDS concentration of the input stream to be $50,000 \mathrm{mg} / \mathrm{l}$ for primary treatment. A pair of well-pads is drilled in such a way that one well-pad has lower TDS concentration in its wastewater and this can be processed with primary treatment, whereas for the second well-pad, the TDS concentration is high and therefore secondary treatment or dilution for primary treatment is required. For example, 
the well-pads W6 and W10, in the case 90\% water availability, have TDS concentrations of $61,051.3 \mathrm{mg} / \mathrm{l}$ and $39,892.5 \mathrm{mg} / \mathrm{l}$, respectively. A similar behavior was found for the case with $80 \%$ water availability, where the first pair, W3 and W6, has TDS concentrations of $36,671.1 \mathrm{mg} / \mathrm{l}$ and 61,051.3 $\mathrm{mg} / \mathrm{l}$, respectively. The second pair, W4 and W10, has TDS concentrations of $106,774.5 \mathrm{mg} / \mathrm{l}$ and $39,892.5 \mathrm{mg} / \mathrm{l}$, respectively. The same pattern can be found for the rest of the case studies. The reduction in fresh water availability is expected to affect the decisions regarding the water management, as shown in Figure 14.

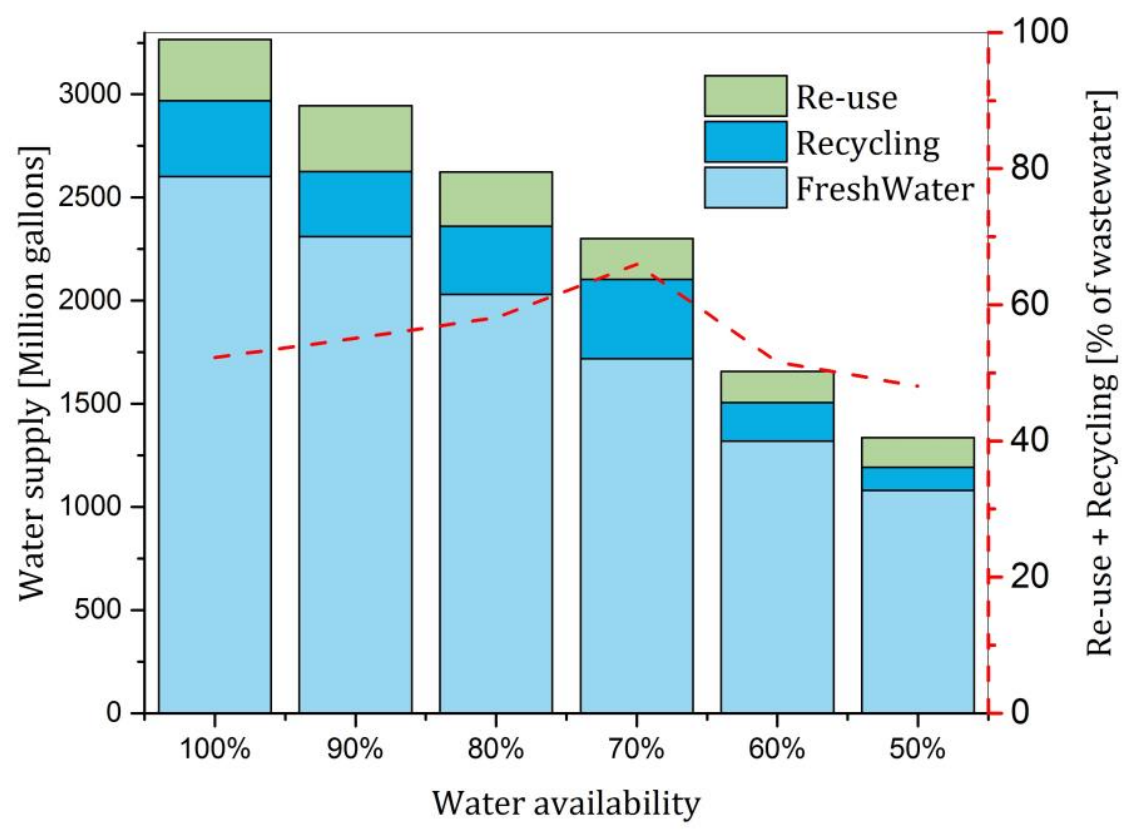

Figure 14. Water management strategy for Case A3

For the base case, the total water consumption was 3,266.5 million gallons; 2,601.5 million gallons (79.6\%) are supplied by the rivers I, II and III, whereas 665.0 million gallons (20.4\%) are supplied by water treatment facilities. The total water consumption varies along with the reduction of fresh water. For the final case, 1,080.3 million gallons (80.9\%) of fresh water were used for drilling and fracturing operations; 255.8 million gallons (19.1\%) are supplied by the water treatment facilities. The total amount of reused water for the first 4 cases, 100\% - 70\% water availability, is virtually the same with an average of 618.6 million gallons. The pattern changes for the cases of $60 \%$ and $50 \%$ water availability, in which 338.5 million gallons and 255.8 million gallons were treated, respectively. The drastic drop in wastewater treatment occurred not only because the fresh water supply decreased, but also the water demand decreased as the MinWI designs became prevalent. 
As a consequence, the water supply relies less on treated water and more on fresh water, reducing capital and operating costs associated with water treatment plants. In general, the results suggest that under water scarcity scenarios, it is preferable to adjust the design of the well-pads to demand less water rather than expanding the infrastructure for water treatment.

Four metrics, two related to economics (cumulative production and breakeven price) and two to water management (water consumption and water re-use/recycle), are used to evaluate the impact of water scarcity on both the economics and the water impacts for Case A1, Case A2, and Case A3 (see Figure 15).
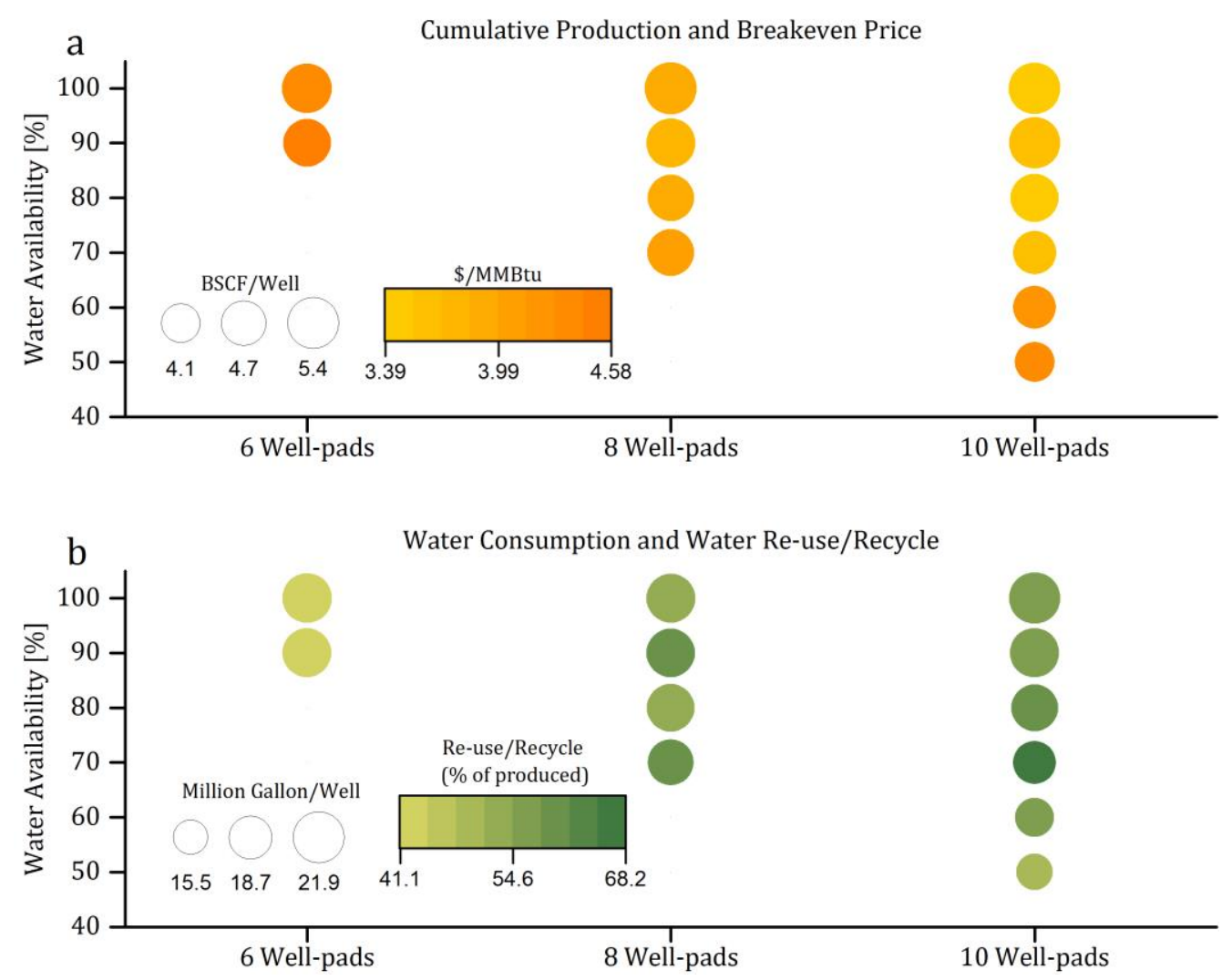

Figure 15. Economics and water management strategy as function of freshwater availability: (a) EUR and breakeven price and (b) Water management strategy.

As the results show, a reduction of $20 \%$ in the water availability would make Case A1 (6 well-pads) economically infeasible. Moreover, Case A2 (8 well-pads) is not profitable if the availability of freshwater resources is reduced by $40 \%$ or more. The optimal NPV decreases monotonically with the increasing water scarcity and increases with the number of well-pads, as shown previously. For instance, for a $10 \%$ of reduction in the available 
freshwater sources, the NPV drops on average $\$ 113.1$ million, $\$ 71.9$ million, and $\$ 101.3$ million for cases A1, A2, and A3, respectively. This is due to a reduction of installation of well-pads with high productivity configuration. Moreover, water scarcity impacts both the estimate ultimate recovery EUR per well (bubbles size in Figure 15a) and the gas breakeven price (color intensity in Figure 15a) of shale gas development. The EUR varies from 4.1 BSCF/well to 5.4 BSCF/well when the availability of freshwater sources varies up to $50 \%$, with low and high EUR values corresponding to scarcity and abundance of freshwater sources, respectively. The variation in the number of well-pads does not significantly affect the EUR, but water availability has a more prominent effect on EUR. This is more evident for Case A3 (10 well-pads), where a reduction of $50 \%$ in fresh water sources generates a cutback of $23.4 \%$, on average, in the productivity of a single well due to the use of less water intensive configurations but which at the same time are less productive. The breakeven price ranges from 3.39 \$/MMBtu to 4.58 \$/MMBtu. As a reference, in 2015, the average prices of domestic natural gas for power plants was about 4.44 \$/MMBtu, while it is expected to raise to 12.56 \$ MMBtu by 2029. In the case of coal, the price for power plants are expected to vary between 1.7 \$/MMBtu and 4.99 \$/MMBtu during the 2015-2029 time frame [106]. In general, at constant water availability, the breakeven price decreases as the number of potential well-pads increases. For instance, as shown previously, at $100 \%$ of water availability, the breakeven price was reduced by 20.9\% from Case A1 to Case A3, which is an effect of economies of scale. Furthermore, at constant number of potential well-pads, the breakeven price, in most cases, tends to increase as the scenarios are more water constrained. For Case A2, the breakeven price increased $4.7 \%$ for a reduction of $40 \%$ in fresh water resources. This variation is more appreciable in Case A3 where the breakeven price increased up to $26.4 \%$ when the fresh water sources were reduced by $50 \%$. These trends are due to a sustained decline in the gas production, which leads to a less efficient use of the transportation and processing infrastructure. Nonetheless, this cannot be generalized as there are two exemptions, such as Case A2, for water availability variation from $100 \%$ to $90 \%$, and Case A3, when available freshwater resources changed from $90 \%$ to $80 \%$, in which the breakeven price shows a reduction of $2.8 \%$ and $1.7 \%$, respectively. For these two cases, the re-scheduling of drilling operations leads to a higher efficiency in the shale gas production, transportation, and 
processing infrastructure. The breakeven price in Case A3 presented a sharp increment when water availability changed from $70 \%$ to $60 \%$ when compared to the trend shown from $100 \%$ to $70 \%$. This can be explained by the variation in the total number of wells along with the reduction in available fresh water. For instance, when water availability ranges from $100 \%$ to $70 \%$, a variation of $10 \%$ results, on average, in a reduction of $8 \%$ in the total number of installed wells. However, once the water resources were constrained from $70 \%$ to $60 \%$, the total installed wells dropped by $21 \%$. The results presented in Figure 15a highlight that water resources are a critical factor in the design of shale gas supply chains and indicate how limited access to water can have negative effects on wellpads productivity and overall economic performance.

The reduction in fresh water availability is also expected to affect decisions regarding the selection of the well-pads configuration and the water management strategy, as shown in Figure 15b. Two alternatives can be implemented in order to tackle production of shale gas under scenarios of water scarcity, these are: selection of less water intensive well-pads designs, and intensification of wastewater treatment processes for increasing water re-use and recycle rates. Each alternative, or their combination, can reduce water consumption in the event of water scarcity. Accordingly, Figure $15 \mathrm{~b}$ presents the variations of water consumption per well (bubbles size) and $\%$ of water re-use plus recycle (color intensity) as function of water availability and number of potential well-pads in the shale gas supply chain. The water consumption, defined here as total fresh water withdrawal minus total treated wastewater that is returned to the freshwater sources, ranges from 15.5 million gallon/well to 21.9 million gallon/well. The water consumption decreases monotonically with the scarcity of fresh water sources driven mostly by an increase in the proportion of less water intensive wells and/or an increase in water re-use and recycle. For instance, for Case A3, in which all the 10 well-pads were always selected regardless of water scarcity, the proportion of less water intensive wells increases monotonically from $\sim 15.5 \%$ to $\sim 79.4 \%$, reducing water consumption, as the availability of fresh water decreases from $100 \%$ to $50 \%$. On the other hand, for Case A2 (8 well-pads), the decrease in water consumption when water availability is reduced from $80 \%$ to $70 \%$ is due only to an increase in water re-use and recycle, since the proportion of less water intensive wells 
remains constant at $\sim 36.4 \%$. However, when water availability is reduced from $90 \%$ to $80 \%$, both water consumption as well as and water re-use and recycle decrease. This reduction in water consumption is only driven by an increase of $\sim 12.0 \%$ in the number of less water intensive wells, which also compensates for the reduction in water re-use and recycle. In Case A2 only 7 well-pads are activated if available fresh water is decreased by $10 \%$ or more. Likewise, in Case A1 (6 well-pads) only 5 well-pads are chosen when the available fresh water is reduced from $100 \%$ to $90 \%$. In this case, water consumption decreases as a consequence of an increase from $30.0 \%$ to $39.1 \%$ in number of less water intensive wells that are selected. This increase also compensates for a reduction of $\sim 2.6 \%$ in re-used and recycled water. The previous situation is also observed in Case A3, when the reduction in the available fresh water decreases by $40 \%$ or more. The $\%$ of water re-use and recycle ranges from $41.1 \%$ to $68.2 \%$ but in some cases it increases to reduce water withdrawal intensity and mitigate the effects of water scarcity. Nevertheless, there is not a monotonic trend for water re-use and recycle as a function of water scarcity.

In a previous work by the authors [13], the concentration of TDS in wastewater and its impact on the drilling strategy, i.e. well-pad configuration and scheduling of drilling and fracturing operations, for the development of shale gas resources was investigated for a case study composed of 5 potential well-pads. In this study, we further explore the effect of wastewater TDS concentration on the economics and water management via parametric analysis for the case study addressed in the previous work ( 5 well-pads), and Case A1 (6 well-pads), Case A2 (8 well-pads), and Case A3 (10 well-pads). The parametric analysis considers $5 \%$ step variations from 0 to $+/-10 \%$ in the wastewater TDS concentration from the base case ( $0 \%$ variation of TDS or original TDS concentrations). Furthermore, the importance of considering the design of well-pads as a key decision variable in the development of shale gas supply chains was addressed. In this case, the optimal well-pad configuration for each base case (0\% variation of TDS) is kept fixed as the TDS concentration changes from $-10 \%$ to $10 \%$. The corresponding results are summarized in Figure 16. 

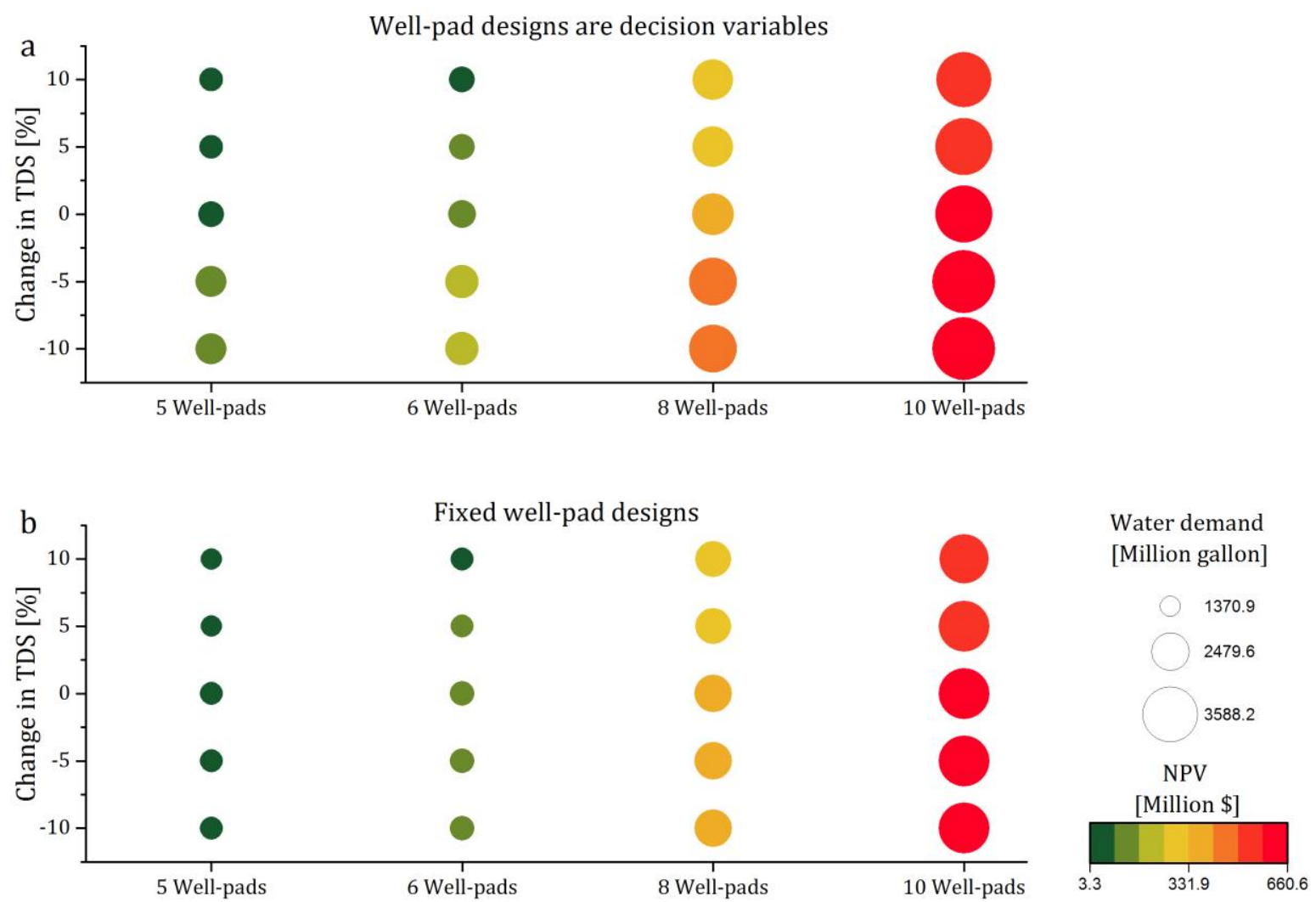

Figure 16. Role of TDS wastewater concentration in shale gas supply chains: (a) well-pad designs are considered decisions variables, and (b) well-pad designs are fixed with variation in TDS concentration.

Higher TDS concentration in wastewater requires intensification of water treatment processes, which increases capital and operating costs. This leads to the selection of less water insensitive configurations for well-pads with relatively high concentrations of TDS or to the deactivation of well-pads where TDS concentration is relatively higher. A reduction of TDS achieves the opposite effect; lower TDS allows processing of larger amounts of wastewater which brings about selection of more water insensitive configurations associated with higher gas productivity, thus increasing the NPV. On average, for adjustable well-pad configurations, a decrease of $10 \%$ in TDS concentration in wastewater allows the wastewater treatment facilities to process more wastewater which relates to higher shale gas production, leading to increments of about $\$ 68.9$ million, $\$ 78.3$ million, $\$ 105.2$ million, and $\$ 76.2$ million on the NPV, for 5 well-pads, 6 well-pads, 8 well-pads, and 10 well-pads, respectively (Figure 16a). On the other hand, for fixed well-pad configurations, the NPV increases only $\$ 7.2$ million, $\$ 10.5$ million, $\$ 14.0$ million, and $\$ 10.8$ million due to the same 
$10 \%$ of decrease in TDS concentration, for the same cases, respectively (Figure 16b). Besides quantifying the effects of TDS concentration on the NPV, these results illustrate the additional benefit of including the well-pad configuration as a decision variable in the strategic design and planning of shale gas supply chains. For the cases previously discussed, the NPV could be improved between $\$ 61.7$ million and $\$ 91.2$ million by optimizing the configuration of the well-pad according to the TDS concentration in wastewater. Another consequence of higher TDS concentration is that the percentage of fresh water utilization in the optimal water supply mix increases. This is also related to the increment of wastewater treatment cost which impacts the amount of total wastewater send to water treatment plants, therefore, more fresh water is required in order to meet water demand and TDS specifications for drilling and fracturing operations associated with the installation of the well-pads. The previous tendencies can be achieved by decreasing the number of installed well-pads or by a better configuration of the well-pads to exploit more efficiently the gas resources. This is intrinsically related to the aforementioned aspect 2, since well-pads with higher productivity are associated with higher number of wells per well-pad, longer horizontal wells, and more fracturing stages. The installation of well-pads with these characteristics boosts the demand for water. For instance, for adjustable wellpad configurations and for the base case of 5 well-pads, 3 out of 5 well-pads were installed with a high productivity configuration. When TDS increased by $10 \%$, the same number of well-pads were chosen to have high gas production, however, in total only 4 well-pads were selected. Consequently, the total water demand dropped by $6.9 \%$. By contrast, by reducing the TDS in $10 \%, 4$ out of 5 well-pads were installed with high gas productivity configuration. Accordingly, the water demand was increased by $21.8 \%$. Similar trends were observed for Case A1, Case A2, and Case A3 in which the variation of TDS in $\pm 10 \%$ affected the number and configuration of the well-pads causing fluctuations in the water demand. For Case A1, the water demand varied from $-6.4 \%$ to $20.4 \%$, for Case A2, these percentages ranged from $-4.2 \%$ to $13.3 \%$, and for Case $\mathrm{A} 3$, the water demand varied from $-3.1 \%$ to 9.8\%. For fixed well-pad configurations, the fluctuations in water demand are less drastic, in fact, the water demand for all the cases is kept constant as the TDS concentration decreases down to $-10 \%$. A slight reduction in the water demand was observed when the TDS increased up to $10 \%$. In this case, the water demand for 5, 6, 8, and 10 well-pad cases 
decreased by $6.8 \%, 6.4 \%, 4.2 \%$, and $3.1 \%$ in comparison to the base case, respectively. These variations are due exclusively to installation of fewer well-pads. Although less noticeable, the wastewater quality associated with the exploitation of shale gas resources also affects decisions concerning the water management strategies in scenarios where the design of the well-pads is not subject to optimization. Regarding the aforementioned aspect 3 , the influence of the TDS concentration on the NPV and water demand subsides as the number of potential well-pads increases. For cases with adjustable well-pad configurations, the NPV decreases by $96.5 \%, 55.9 \%, 32.1 \%$, and $16.7 \%$ when TDS concentration ranges from $-10 \%$ to $+10 \%$, for $5,6,8$, and 10 well-pads, respectively. Similarly, the water demand drops by $23.6 \%, 22.6 \%, 15.4 \%$, and $11.8 \%$, for the same cases, respectively. Likewise, for cases in which the configuration of the well-pads is not a decision variable, the NPV presents comparable variations of $90.2 \%, 32.0 \%, 14.3 \%$, and $7.6 \%$, whereas for water demand the variations are $6.9 \%, 6.4 \%, 4.2 \%$, and $3.1 \%$ for $5,6,8$, and 10 well-pads, respectively. This behavior can be linked to the fact that as the number of potential wellpads increases so does the number of alternatives for reconfiguration of the well-pads designs and/or the optimal drilling and fracturing schemes, which favors solutions that mitigate to a certain extent the variations in the water and wastewater quality.

Here we highlight three important findings from the previous analysis: (1) there is an inverse relationship between the TDS concentration in wastewater and the corresponding NPV of the cases presented, (2) the water demand for drilling and fracturing operations tends to decrease as the concentration of TDS in wastewater increases, and (3) as the number of potential well-pads increases, the design of the shale gas supply chain becomes more resilient to changes in the wastewater quality. In addition, it is worth mentioning that although the wastewater management strategy seems more stable for cases with fixed well-pads designs, their economic performance is, in general, severely affected. Hence, a comprehensive planning and design of shale gas supply chains should exploit the advantages of optimizing the configuration of well-pads. Finally, it is noteworthy that wastewater quality, e.g., TDS concentration, varies also temporally $[13,107,108]$. This situation represents additional issues for wastewater management in shale gas operations $[107,108]$. 


\section{Key findings and implications}

This study focused on the interplay between water management, well-pad and supply chain design, and economy of scale in shale gas development. Economies of scale were evaluated by increasing the number of well-pads in the system, which reduces the gas breakeven price and allows a higher use of treated water in fracturing operations. Consequently, even though the total fresh water withdrawal increases with the number of well-pads that are selected, the water withdrawal intensity decreases as the scale of the shale gas development increases, which could be interpreted as higher efficiency in the use of water sources. The analysis of water-energy nexus was based on parametric analysis of fresh water availability and TDS concentration in wastewater, which are two key parameters that could affect the optimal drilling and fracturing scheme as well as the water management strategy and thus the economics of the shale gas development. Under water scarcity scenarios, which are becoming progressively more frequent given global climate events such as El Niño/La Niña, it seems that the selection of less water intensive well-pad designs is more cost-effective than intensifying water treatment processes for water re-use and/or recycle in the development of shale gas resources. For the case studies presented here, it was also found that a reduction of $10 \%$ in the availability of fresh water sources reduced the profitability of shale gas development by more than $\$ 71.9$ million. Therefore, the accuracy of water availability assessments is crucial at designing and planning shale gas supply chains. The results from the parametric analysis involving the TDS concentration in wastewater reaffirm our findings regarding the role of well-pad configurations in the resilience of the shale gas supply chain. For instance, as TDS concentration increases, the configuration of well-pads shifts to less water intensive designs, which leads to a decrease in wastewater flowrates as well as in gas production affecting the profitability of the shale gas development. Thus, TDS concentration in wastewater is also an important factor to consider in the development of shale gas resources. Specifically, the share of fresh water sources in the water supply mix increases as a response to higher TDS concentrations in wastewater. Therefore, more attention needs to be directed to the accurate characterization of wastewater in shale gas operations. Finally, it was possible to address quantitatively the interdependency of important aspects of shale gas supply chains, which 
demonstrates the advantages of implementing mathematical optimization frameworks to extract synergies that otherwise are difficult to elucidate.

\section{Supporting information}

Data corresponding to Figure 2 can be found in the excel file "Data Figure 2.xlsx".

\section{Acknowledgments}

The authors would like to acknowledge the financial support from the Colombian Science Council (COLCIENCIAS) and the Colombia Purdue Institute (CPI).

\section{References}

[1] International Energy Agency (IEA). Golden rules for a golden age of gas. London: 2012.

[2] Agerton M, Hartley P, III KM, Temzelides T. Employment Impacts of Upstream Oil and Gas Investment in the United States. IMF Work Pap 2015;62:171-80. doi:10.1016/j.eneco.2016.12.012.

[3] Zhang D, Yang T. Environmental impacts of hydraulic fracturing in shale gas development in the United States. Pet Explor Dev 2015;42:876-83. doi:10.1016/S1876-3804(15)30085-9.

[4] Jarvie DM, Hill RJ, Ruble TE, Pollastro RM. Unconventional shale-gas systems: The Mississippian Barnett Shale of north-central Texas as one model for thermogenic shale-gas assessment. Am Assoc Pet Geol Bull 2007;91:475-99. doi:10.1306/12190606068.

[5] Curtis JB. Fractured shale-gas systems. Am Assoc Pet Geol Bull 2002;86:1921-38. doi:10.1306/61EEDDBE-173E-11D7-8645000102C1865D.

[6] Wang L, Wang S, Zhang R, Wang C, Xiong Y, Zheng X, et al. Review of multi-scale and multi-physical simulation technologies for shale and tight gas reservoirs. J Nat Gas Sci Eng 2017;37:560-78. doi:10.1016/j.jngse.2016.11.051.

[7] Gale JFW, Laubach SE, Olson JE, Eichhuble P, Fall A. Natural Fractures in shale: A review and new observations. Am Assoc Pet Geol Bull 2014;98:2165-216. doi:10.1306/08121413151.

[8] Cipolla C, Lolon E, Erdle J, Rubin B. Reservoir Modeling in Shale-Gas Reservoirs. SPE Reserv Eval Eng 2010;13. doi:10.2118/125530-PA.

[9] Mayerhofer M, Lolon E, Warpinski N, Cipolla C, Walser D, Rightmire C. What Is Stimulated Reservoir Volume? SPE Prod Oper 2010;25:16-8. doi:10.2118/119890-PA.

[10] Weijermars R. Economic appraisal of shale gas plays in Continental Europe. Appl Energy 2013;106:100-15. doi:10.1016/j.apenergy.2013.01.025.

[11] Calderón AJ, Guerra OJ, Papageorgiou LG, Siirola JJ, Reklaitis G V. Preliminary Evaluation of Shale Gas Reservoirs: Appraisal of Different Well-Pad Designs via Performance Metrics. Ind Eng Chem Res 2015;54:10334-49. doi:10.1021/acs.iecr.5b01590.

[12] Wilson KC, Durlofsky LJ. Optimization of shale gas field development using direct search techniques and reduced-physics models. J Pet Sci Eng 2013;108:304-15. doi:10.1016/j.petrol.2013.04.019.

[13] Guerra OJ, Calderón AJ, Papageorgiou LG, Siirola JJ, Reklaitis G V. An optimization framework for the integration of water management and shale gas supply chain design. Comput Chem Eng 2016;92:23055. doi:10.1016/j.compchemeng.2016.03.025. 
[14] Cafaro DC, Grossmann IE. Strategic planning, design, and development of the shale gas supply chain network. AIChE J 2014;60:2122-42. doi:10.1002/aic.14405.

[15] Arredondo-Ramírez K, Ponce-Ortega JM, El-Halwagi MM. Optimal planning and infrastructure development for shale gas production. Energy Convers Manag 2016;119:91-100. doi:10.1016/j.enconman.2016.04.038.

[16] Gao J, You F. Design and optimization of shale gas energy systems: Overview, research challenges, and future directions. Comput Chem Eng 2017;106:699-718. doi:10.1016/j.compchemeng.2017.01.032.

[17] Bartholomew T V., Mauter MS. Multiobjective Optimization Model for Minimizing Cost and Environmental Impact in Shale Gas Water and Wastewater Management. ACS Sustain Chem Eng 2016;4:3728-35. doi:10.1021/acssuschemeng.6b00372.

[18] Burnham A, Han J, Clark CE, Wang M, Dunn JB, Palou-Rivera I. Life-cycle greenhouse gas emissions of shale gas, natural gas, coal, and petroleum. Environ Sci Technol 2012;46:619-27. doi:10.1021/es201942m.

[19] Howarth RW, Santoro R, Ingraffea A. Methane and the greenhouse-gas footprint of natural gas from shale formations. Clim Change 2011;106:679-90. doi:10.1007/s10584-011-0061-5.

[20] Weber CL, Clavin C. Life cycle carbon footprint of shale gas: review of evidence and implications. Environ Sci Technol 2012;46:5688-95. doi:10.1021/es300375n.

[21] International Energy Agency (IEA). World Energy Outlook 2015. Paris: 2015.

[22] Kavalov B, Petric H, Georgakaki A. Liquefied natural gas for Europe: some important issues for consideration. Brussels: 2009. doi:10.2790/1045.

[23] Murphy DJ, Hall C a S, Dale M, Cleveland C. Order from chaos: A preliminary protocol for determining the EROI of fuels. Sustainability 2011;3:1888-907. doi:10.3390/su3101888.

[24] Hu Y, Hall CAS, Wang J, Feng L, Poisson A. Energy Return on Investment (EROI) of China's conventional fossil fuels: Historical and future trends. Energy 2013;54:352-64. doi:10.1016/j.energy.2013.01.067.

[25] Wang J, Mohr S, Feng L, Liu H, Tverberg GE. Analysis of resource potential for China's unconventional gas and forecast for its long-term production growth. Energy Policy 2016;88:389-401. doi:10.1016/j.enpol.2015.10.042.

[26] Yeh S, Ghandi A, Scanlon BR, Brandt AR, Cai H, Wang MQ, et al. Energy Intensity and Greenhouse Gas Emissions from Oil Production in the Eagle Ford Shale. Energy \& Fuels 2017;31:1440-9. doi:10.1021/acs.energyfuels.6b02916.

[27] Aucott ML, Melillo JM. A preliminary energy return on investment analysis of natural gas from the marcellus shale. J Ind Ecol 2013;17:668-79. doi:10.1111/jiec.12040.

[28] International Energy Agency (IEA). Natural Gas Information 2015. Paris: IEA; 2015.

[29] International Gas Union (IGU). World LNG Report. 2015.

[30] International Association of Oil \& Gas Producers (IOGP). Shale Gas and Europe 2016.

[31] Bloomberg. China's shale gas reserves jump fivefold as output lags target 2016.

[32] Tollefson J. China slow to tap shale-gas bonanza. Nature 2013;494:294-294. doi:10.1038/494294a.

[33] Bloomberg. PetroChina, sinopec 2015 shale output said below China goal 2015.

[34] West Virginia GIS Technical Center. Global Atlas of Unconventional Hydrocarbon Resources 2014.

[35] Reig P, Luo T, Proctor JN. Global shale gas development: Water availability and busines risks. Washington, D.C.: 2014.

[36] Gassert F, Landis M, Luck M, Reig P, Shiao T. Aqueduct Global Maps 2.1. Washington, DC: 2013.

[37] Scanlon BR, Reedy RC, Philippe Nicot J. Will water scarcity in semiarid regions limit hydraulic fracturing of shale plays? Environ Res Lett 2014;9:124011. doi:10.1088/1748-9326/9/12/124011. 
[38] Breyer JA. Shale Reservoirs-Giant Resources for the 21st Century. American Association of Petroleum Geologists (AAPG); 2012.

[39] Lozano Maya JR. The united states experience as a reference of success for shale gas development: The case of mexico. Energy Policy 2013;62:70-8. doi:10.1016/j.enpol.2013.07.088.

[40] Bilgili F, Koçak E, Bulut Ü, Sualp MN. How did the US economy react to shale gas production revolution? An advanced time series approach. Energy 2016;116:963-77. doi:10.1016/j.energy.2016.10.056.

[41] Energy Information Administration (EIA). NATURAL GAS - U.S. Natural gas imports 2016. https://www.eia.gov/dnav/ng/hist/n9100us2a.htm.

[42] Energy Information Administration (EIA). NATURAL GAS - U.S. Natural gas exports 2016. https://www.eia.gov/dnav/ng/hist/n9130us2a.htm.

[43] Hammond GP, O'Grady Á. Indicative energy technology assessment of UK shale gas extraction. Appl Energy 2017;185:1907-18. doi:10.1016/j.apenergy.2016.02.024.

[44] De Silva PNK, Simons SJR, Stevens P. Economic impact analysis of natural gas development and the policy implications. Energy Policy 2016;88:639-51. doi:10.1016/j.enpol.2015.09.006.

[45] Energy Information Administration (EIA). TOTAL ENERGY - Electricity net generation: Electric power sector 2016. https://www.eia.gov/totalenergy/data/browser/?tbl=T07.02B\#/?f=A.

[46] American Chemistry Council (ACC). Shale Gas, Competitiveness, and New US Chemical Industry Investment: An analysis based on announced Projects. 2013.

[47] American Chemistry Council (ACC). Shale gas and new U.S. chemical industry investment: \$138 billion and counting. 2015.

[48] Energy Information Administration (EIA). Petroleum \& Other Liquids 2016. https://www.eia.gov/petroleum/drilling/\#tabs-summary-2.

[49] Energy Information Administration (EIA). Short-Term Energy Outlook 2016.

[50] Energy Information Administration (EIA). Spot Prices for Crude Oil and Petroleum Products 2016. https://www.eia.gov/dnav/pet/pet_pri_spt_s1_d.htm.

[51] Energy Information Administration (EIA). Henry Hub Natural Gas Spot Price 2016. https://www.eia.gov/dnav/ng/hist/rngwhhdd.htm.

[52] The World Bank. Commodity Markets 2016. http://www.worldbank.org/en/research/commoditymarkets.

[53] Energy Information Administration (EIA). Annual Energy Outlook 2017. 2017.

[54] Jiang M, Michael Griffin W, Hendrickson C, Jaramillo P, VanBriesen J, Venkatesh A. Life cycle greenhouse gas emissions of Marcellus shale gas. Environ Res Lett 2011;6:34014. doi:10.1088/17489326/6/3/034014.

[55] Caulton DR, Shepson PB, Santoro RL, Sparks JP, Howarth RW, Ingraffea AR, et al. Toward a better understanding and quantification of methane emissions from shale gas development. Proc Natl Acad Sci 2014;111:6237-42. doi:10.1073/pnas.1316546111.

[56] Heath GA, O'Donoughue P, Arent DJ, Bazilian M. Harmonization of initial estimates of shale gas life cycle greenhouse gas emissions for electric power generation. Proc Natl Acad Sci 2014;111:E3167-76. doi:10.1073/pnas.1309334111.

[57] Tollefson J. Air sampling reveals high emissions from gas field. Nature 2012;482:139-40. doi:10.1038/482139a.

[58] Karion A, Sweeney C, Pétron G, Frost G, Michael Hardesty R, Kofler J, et al. Methane emissions estimate from airborne measurements over a western United States natural gas field. Geophys Res Lett 2013;40:4393-7. doi:10.1002/grl.50811.

[59] Pétron G, Frost G, Miller BR, Hirsch AI, Montzka SA, Karion A, et al. Hydrocarbon emissions 
characterization in the Colorado Front Range: A pilot study. J Geophys Res Atmos 2012;117:n/a-n/a. doi:10.1029/2011JD016360.

[60] Newell RG, Raimi D. Implications of Shale Gas Development for Climate Change. Environ Sci Technol 2014;48:8360-8. doi:10.1021/es4046154.

[61] Shearer C, Bistline J, Inman M, Davis SJ. The effect of natural gas supply on US renewable energy and CO 2 emissions. Environ Res Lett 2014;9:94008. doi:10.1088/1748-9326/9/9/094008.

[62] Jenner S, Lamadrid AJ. Shale gas vs. coal: Policy implications from environmental impact comparisons of shale gas, conventional gas, and coal on air, water, and land in the United States. Energy Policy 2013;53:442-53. doi:10.1016/j.enpol.2012.11.010.

[63] McJeon H, Edmonds J, Bauer N, Clarke L, Fisher B, Flannery BP, et al. Limited impact on decadal-scale climate change from increased use of natural gas. Nature 2014;514:482-5. doi:10.1038/nature13837.

[64] Zhang X, Myhrvold NP, Caldeira K. Key factors for assessing climate benefits of natural gas versus coal electricity generation. Environ Res Lett 2014;9:114022. doi:10.1088/1748-9326/9/11/114022.

[65] Sovacool BK. How long will it take? Conceptualizing the temporal dynamics of energy transitions. Energy Res Soc Sci 2016;13:202-15. doi:10.1016/j.erss.2015.12.020.

[66] Smil V. The Long Slow Rise of Solar and Wind. Sci Am 2014;310:52-7. doi:10.1038/scientificamerican0114-52.

[67] Smil V. Examining energy transitions: A dozen insights based on performance. Energy Res Soc Sci 2016;22:194-7. doi:10.1016/j.erss.2016.08.017.

[68] Guerra OJ, Reklaitis GV. Advances and challenges in water management within energy systems. Renew Sustain Energy Rev 2017. doi:10.1016/j.rser.2017.10.071.

[69] Clark CE, Horner RM, Harto CB. Life cycle water consumption for shale gas and conventional natural gas. Environ Sci Technol 2013;47:11829-36. doi:10.1021/es4013855.

[70] Nicot J-P, Scanlon BR. Water use for Shale-gas production in Texas, U.S. Environ Sci Technol 2012;46:3580-6. doi:10.1021/es204602t.

[71] Jackson RB, Vengosh A, Carey JW, Davies RJ, Darrah TH, O'Sullivan F, et al. The Environmental Costs and Benefits of Fracking. Annu Rev Environ Resour 2014. doi:10.1146/annurev-environ-031113144051.

[72] Olmstead SM, Muehlenbachs LA, Shih J, Chu Z, Krupnick AJ. Shale gas development impacts on surface water quality in Pennsylvania. Proc Natl Acad Sci U S A 2013;110:4962-7. doi:10.1073/pnas.1213871110.

[73] Vidic RD, Brantley SL, Vandenbossche JM, Yoxtheimer D, Abad JD. Impact of Shale Gas Development on Regional Water Quality. Science 2013;340:1235009-1235009. doi:10.1126/science.1235009.

[74] Vengosh A, Jackson RB, Warner N, Darrah TH, Kondash A. A critical review of the risks to water resources from unconventional shale gas development and hydraulic fracturing in the United States. Environ Sci Technol 2014;48:8334-48. doi:10.1021/es405118y.

[75] Burgos WD, Castillo-Meza L, Tasker TL, Geeza TJ, Drohan PJ, Liu X, et al. Watershed-Scale Impacts from Surface Water Disposal of Oil and Gas Wastewater in Western Pennsylvania. Environ Sci Technol 2017;51:8851-60. doi:10.1021/acs.est.7b01696.

[76] Osborn SG, Vengosh A, Warner NR, Jackson RB. Methane contamination of drinking water accompanying gas-well drilling and hydraulic fracturing. Proc Natl Acad Sci U S A 2011;108:8172-6. doi:10.1073/pnas.1100682108.

[77] Jackson RB, Vengosh A, Darrah TH, Warner NR, Down A, Poreda RJ, et al. Increased stray gas abundance in a subset of drinking water wells near Marcellus shale gas extraction. Proc Natl Acad Sci U S A 2013;110:11250-5. doi:10.1073/pnas.1221635110.

[78] Ellsworth WL. Injection-Induced Earthquakes. Science 2013;341:1225942-1225942. doi:10.1126/science.1225942. 
[79] Keranen K, Weingarten M, Abers G. Sharp increase in central Oklahoma seismicity since 2008 induced by massive wastewater injection. Science 2014;345:448-51. doi:10.1038/45144.

[80] Gregory KB, Vidic RD, Dzombak D a. Water management challenges associated with the production of shale gas by hydraulic fracturing. Elements 2011;7:181-6. doi:10.2113/gselements.7.3.181.

[81] Lutz BD, Lewis AN, Doyle MW. Generation, transport, and disposal of wastewater associated with Marcellus Shale gas development. Water Resour Res 2013;49:647-56. doi:10.1002/wrcr.20096.

[82] Rahm BG, Bates JT, Bertoia LR, Galford AE, Yoxtheimer DA, Riha SJ. Wastewater management and Marcellus Shale gas development: Trends, drivers, and planning implications. J Environ Manage 2013;120:105-13. doi:10.1016/j.jenvman.2013.02.029.

[83] Bilgen S, Sarıkaya İ. New horizon in energy: Shale gas. J Nat Gas Sci Eng 2016;35:637-45. doi:10.1016/j.jngse.2016.09.014.

[84] Silva TLS, Morales-Torres S, Castro-Silva S, Figueiredo JL, Silva AMT. An overview on exploration and environmental impact of unconventional gas sources and treatment options for produced water. J Environ Manage 2017;200:511-29. doi:10.1016/j.jenvman.2017.06.002.

[85] Shrestha N, Chilkoor G, Wilder J, Gadhamshetty V, Stone JJ. Potential water resource impacts of hydraulic fracturing from unconventional oil production in the Bakken shale. Water Res 2017;108:124. doi:10.1016/j.watres.2016.11.006.

[86] Torres L, Yadav OP, Khan E. A review on risk assessment techniques for hydraulic fracturing water and produced water management implemented in onshore unconventional oil and gas production. Sci Total Environ 2016;539:478-93. doi:10.1016/j.scitotenv.2015.09.030.

[87] Maloney KO, Young JA, Faulkner SP, Hailegiorgis A, Slonecker ET, Milheim LE. A detailed risk assessment of shale gas development on headwater streams in the Pennsylvania portion of the Upper Susquehanna River Basin, U.S.A. Sci Total Environ 2018;610-611:154-66. doi:10.1016/j.scitotenv.2017.07.247.

[88] Castro-Alvarez F, Marsters P, Ponce de León Barido D, Kammen DM. Sustainability lessons from shale development in the United States for Mexico and other emerging unconventional oil and gas developers. Renew Sustain Energy Rev 2018;82:1320-32. doi:10.1016/j.rser.2017.08.082.

[89] Koleva MN, Polykarpou EM, Liu S, Styan CA, Papageorgiou LG. Optimal design of water treatment processes. Desalin Water Treat 2016;57:26954-75. doi:10.1080/19443994.2016.1173595.

[90] Horner P, Halldorson B, Slutz JA. Shale Gas Water Treatment Value Chain - A Review of Technologies, including Case Studies. SPE Annu. Tech. Conf. Exhib., Society of Petroleum Engineers; 2013. doi:10.2118/147264-MS.

[91] Boudet H, Clarke C, Bugden D, Maibach E, Roser-Renouf C, Leiserowitz A. "Fracking” controversy and communication: Using national survey data to understand public perceptions of hydraulic fracturing. Energy Policy 2014;65:57-67. doi:10.1016/j.enpol.2013.10.017.

[92] Whitmarsh L, Nash N, Upham P, Lloyd A, Verdon JP, Kendall JM. UK public perceptions of shale gas hydraulic fracturing: The role of audience, message and contextual factors on risk perceptions and policy support. Appl Energy 2015;160:419-30. doi:10.1016/j.apenergy.2015.09.004.

[93] Evensen D, Stedman R. Scale matters: Variation in perceptions of shale gas development across national, state, and local levels. Energy Res Soc Sci 2016;20:14-21. doi:10.1016/j.erss.2016.06.010.

[94] Thomas M, Pidgeon N, Evensen D, Partridge T, Hasell A, Enders C, et al. Public perceptions of hydraulic fracturing for shale gas and oil in the United States and Canada. Wiley Interdiscip Rev Clim Chang 2017:e450. doi:10.1002/wcc.450.

[95] Clough E, Bell D. Just fracking: a distributive environmental justice analysis of unconventional gas development in Pennsylvania, USA. Environ Res Lett 2016;11:25001. doi:10.1088/17489326/11/2/025001.

[96] Whitton J, Brasier K, Charnley-Parry I, Cotton M. Shale gas governance in the United Kingdom and the United States: Opportunities for public participation and the implications for social justice. Energy Res 
Soc Sci 2017;26:11-22. doi:10.1016/j.erss.2017.01.015.

[97] Kuchler M. Post-conventional energy futures: Rendering Europe's shale gas resources governable. Energy Res Soc Sci 2017;31:32-40. doi:10.1016/j.erss.2017.05.028.

[98] Lozano-Maya JR. Looking through the prism of shale gas development: Towards a holistic framework for analysis. Energy Res Soc Sci 2016;20:63-72. doi:10.1016/j.erss.2016.05.014.

[99] Konschnik KE, Boling MK. Shale gas development: a smart regulation framework. Environ Sci Technol 2014;48:8404-16. doi:10.1021/es405377u.

[100] Computer Modeling Group. GEM User's Guide: Advance Compositional Reservoir Simulatior, Version 2014. Computer Modeling Group Ltd. Houston: 2014.

[101] Guarnone M, Rossi F, Negri E, Grassi C, Genazzi D, Zennaro R. An unconventional mindset for shale gas surface facilities. J Nat Gas Sci Eng 2012;6:14-23. doi:10.1016/j.jngse.2012.01.002.

[102] Yuan J, Luo D, Xia L, Feng L. Policy recommendations to promote shale gas development in China based on a technical and economic evaluation. Energy Policy 2015;85:194-206. doi:10.1016/j.enpol.2015.06.006.

[103] Unidad de Planeación Minero Energética -UPME. Plan de Expansion de Referencia Generacion Transmisión 2014-2028. Bogotá/Colombia: 2014.

[104] ESRI. ArcGIS Desktop: Release 10.2.2. Redlands, CA: Environmental Systems Research Institute. 2014.

[105] Nicot J-P, Scanlon BR, Reedy RC, Costley RA. Source and fate of hydraulic fracturing water in the Barnett Shale: a historical perspective. Environ Sci Technol 2014;48:2464-71. doi:10.1021/es404050r.

[106] Unidad de Planeación Minero Energética -UPME. Proyección de Demanda de Energía Eléctrica y Potencia Máxima en Colombia-Revisión Marzo de 2015. Bogotá/Colombia: 2015.

[107] Rosenblum J, Nelson AW, Ruyle B, Schultz MK, Ryan JN, Linden KG. Temporal characterization of flowback and produced water quality from a hydraulically fractured oil and gas well. Sci Total Environ 2017;596-597:369-77. doi:10.1016/j.scitotenv.2017.03.294.

[108] Kondash AJ, Albright E, Vengosh A. Quantity of flowback and produced waters from unconventional oil and gas exploration. Sci Total Environ 2017;574:314-21. doi:10.1016/j.scitotenv.2016.09.069. 